\title{
WestVirginiaUniversity
}

THE RESEARCH REPOSITORY @ WVU

Graduate Theses, Dissertations, and Problem Reports

2012

\section{Three Essays on International Trade and Labor Market Flexibility}

Shadrack Mwilaria

West Virginia University

Follow this and additional works at: https://researchrepository.wvu.edu/etd

\section{Recommended Citation}

Mwilaria, Shadrack, "Three Essays on International Trade and Labor Market Flexibility" (2012). Graduate Theses, Dissertations, and Problem Reports. 4901.

https://researchrepository.wvu.edu/etd/4901

This Dissertation is protected by copyright and/or related rights. It has been brought to you by the The Research Repository @ WVU with permission from the rights-holder(s). You are free to use this Dissertation in any way that is permitted by the copyright and related rights legislation that applies to your use. For other uses you must obtain permission from the rights-holder(s) directly, unless additional rights are indicated by a Creative Commons license in the record and/ or on the work itself. This Dissertation has been accepted for inclusion in WVU Graduate Theses, Dissertations, and Problem Reports collection by an authorized administrator of The Research Repository @ WVU.

For more information, please contact researchrepository@mail.wvu.edu. 
Three Essays on International Trade and Labor Market Flexibility

\author{
Dissertation \\ by \\ Shadrack Mwilaria \\ Submitted to the College of Business and Economics \\ at West Virginia University \\ in partial fulfillment of the requirements for the degree of

\section{Doctor of Philosophy \\ in \\ Economics}
Peter Schaeffer, Ph.D. (Chairperson and Advisor), Shuichiro Nishioka, Ph.D. (Advisor),
Tesfa Gebremedhin, Ph.D., Arabinda Basistha, Ph.D.,
Stratford Douglas, Ph.D.,
Department of Economics Morgantown, WV, 26506, USA. \\ August 2012
}

Keywords: Export Specialization; Industry-Specific Volatility; Labor Flexibility; Trade Protection; Trade and Labor Market Interactions; Unemployment. 
Abstract

\section{Three Essays on International Trade and Labor Market Flexibility}

\section{Shadrack Mwilaria}

Differences in labor laws and regulations are believed to have profound effects on the flow of jobs and workers within and across industries. The speed of these flows consequently influence global trade patterns, either negatively or positively. Many countries are reluctant to change existing regulations in their labor market as well as regulations on trade because they believe such changes would have negative implication on their export industries and jobs. This dissertation consists of three essays that look at these issues by examining how labor institutions interact with industry-level factors and their effects on export specialization, trade barriers and employment.

In the first chapter, I examine the type of global specialization patterns that arise as a result of the advantage generated by the flexibility of labor in a country. In particular, I use country-industry pooled data to examine the relationship between industry-specific volatility, labor market flexibility and export specialization. I find that interactions between labor flexibility, industry-specific volatility and industry-level capital intensity play an important role in determining the structure of global export specialization. The second chapter shows that in addition to various industry-level factors that influence protectionism, interactions between labor institutions and industry-specific volatility partially explain changes in tariff levels across industries and countries. Using industry-level data across many countries, and employing the political-economy theory of endogenoustrade protection, I show that industry-specific volatility partially explain average tariffs across industries and countries. The third chapter provides evidence that trade policies effect jobs across less developed countries. Reducing trade barriers lowers unemployment among unskilled workers but increases unemployment for skilled workers. These two effects cancel each other, such that trade policies do not seem to have any effects on the overall unemployment across less developed countries. 


\section{TABle of Contents}

Chapter 1: Structure of Industrial Specialization, Volatility and Labor Mar-

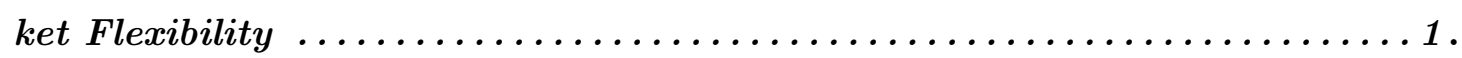

Acknowledgment $\ldots \ldots \ldots \ldots \ldots \ldots \ldots \ldots \ldots \ldots \ldots \ldots \ldots \ldots \ldots \ldots$ viii.

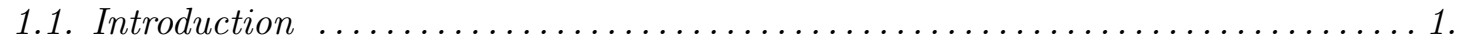

1.2. Flexibility of the Labor Market ................................... 3.

1.2.1. Cost of adjusting hours worked ................................. 3.

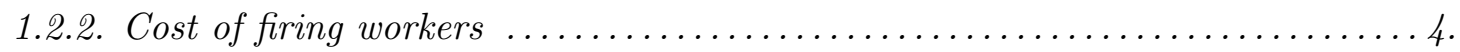

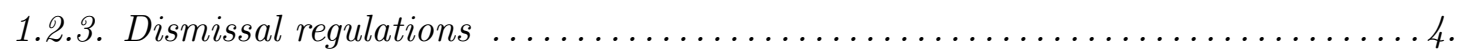

1.2.4. Limitations of the labor flexibility index ............................. 5 .

1.3. Export specialization patterns .................................... 5 .

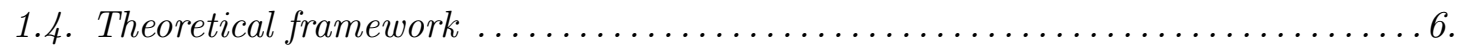

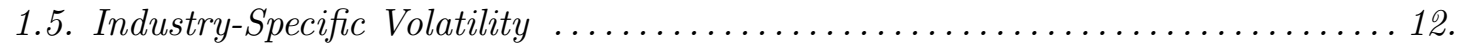

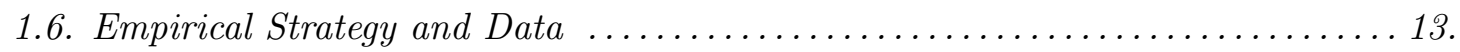

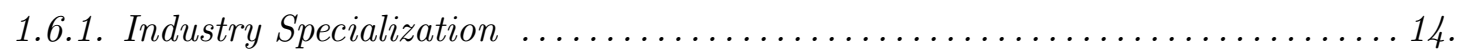

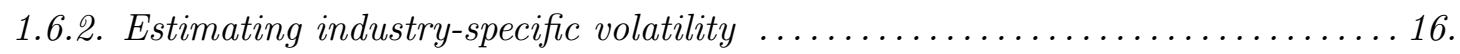

1.7. Empirical Model ................................................ 16.

1.7.1. A Probit estimation ............................................ 17.

1.8. Results and Discussion ........................................ 18 .

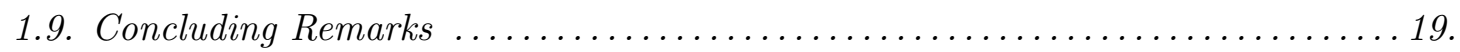




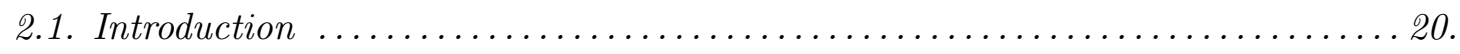

2.2. Determination of Trade Barriers ................................ 21 .

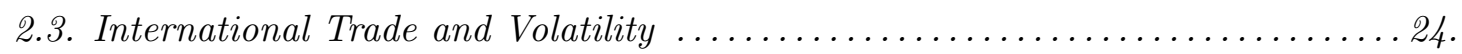

2.4. Theoretical Framework ..................................... 25 .

2.5. Empirical Strategy and Model Specification ............................ 30.

2.5.1. Variables capturing demand for protection $\ldots \ldots \ldots \ldots \ldots \ldots \ldots \ldots .$.

2.5.1.1. Industry volatility $\ldots \ldots \ldots \ldots \ldots \ldots \ldots \ldots \ldots \ldots \ldots \ldots \ldots \ldots \ldots \ldots \ldots \ldots \ldots \ldots \ldots .$.

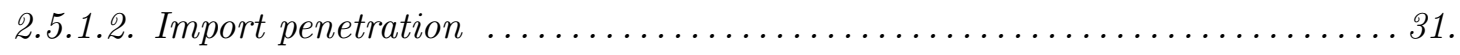

2.5.1.3. Share of industry export in gross output ........................... 31 .

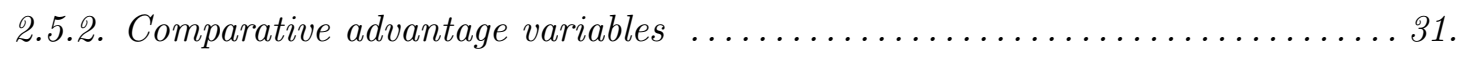

2.5.2.1. Interaction of volatility and labor flexibility ........................ 31 .

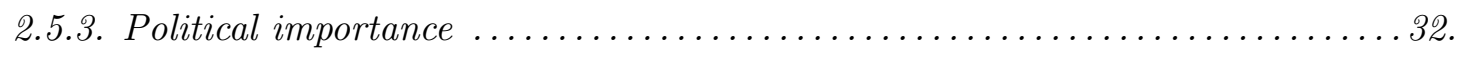

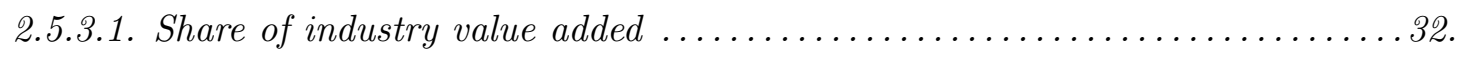

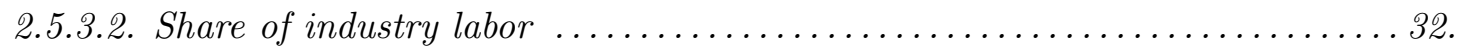

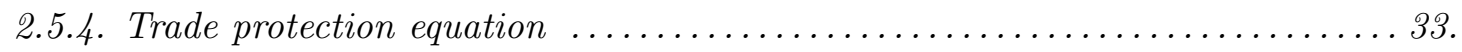

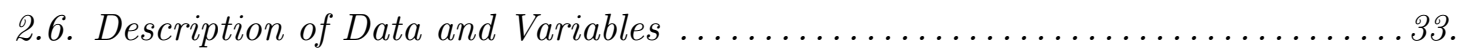

2.7. Discussion of Estimated Results ..................................... 37.

2.8. Concluding Remarks ......................................... 38 . 
Chapter 3: International Trade, Labor Market Flexibility, and Unemployment: empirical evidence from less developed countries ..............39.

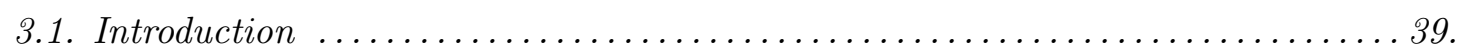

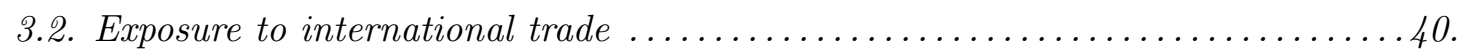

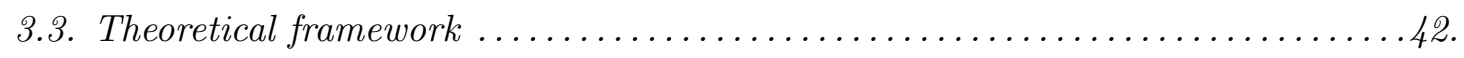

3.3.1. Labor MArket .............................................. 44 .

3.4. Unemployment and the Flexibility of Labor Market ..................... 48 .

3.5. Data Description and the Model ...................................

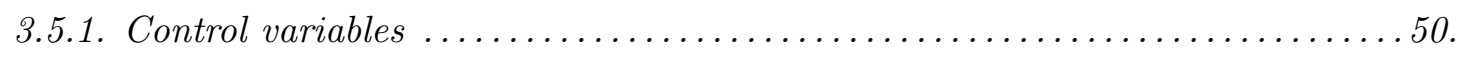

3.5.2. Endogeneity of trade policy and instrumental variable estimation ......... 52.

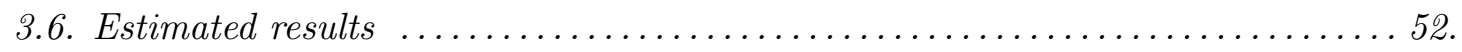

3.7. Concluding Remarks ........................................... 53. 


\section{List of Figures}

Fig. 1. Log GDP and labor flexibility index for both developed and less developed . . 5\%.

Fig. 2. Log GDP and labor flexibility index for developed countries ..............58.

Fig. 3. Log GDP and labor flexibility index for less developed countries ..........59.

Fig. 4. Trade (exports plus imports divided by output) and volatility ............60.

Fig. 5. Relationships between tariffs and volatility of value added .............6. 61 .

Fig. 6. Unemployment rate and tariff rate (simple $M F N$ tariff rate) $\ldots \ldots \ldots \ldots$.......

Fig. 7. Correlation between unemployment and labor flexibility ...............63. 


\section{List of Tables}

1. Values of labor index constructed by Botero et al. (2004) and GDP per capita, PPP

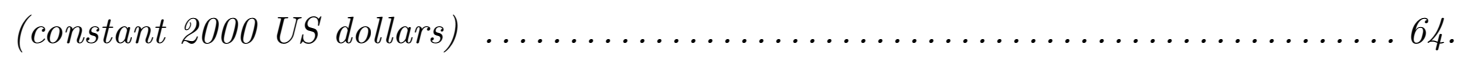

2. Revealed Comparative Advantage values for Austria and Czech Republic .......65.

3. Standard deviation and variance of the growth rate of value added for 28 manufac-

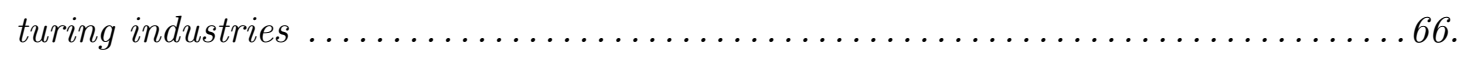

4. Standard deviation and variance of the growth rate of value added at industry-level 67.

5. Estimated results with industry and country fixed effects .................68.

6. A Probit estimations ...........................................6. 69 .

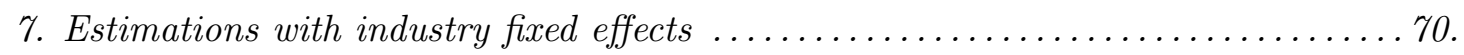

8. Estimations with country fixed effects ............................... 71 .

9. Estimations with industry and country fixed effects .................... 72.

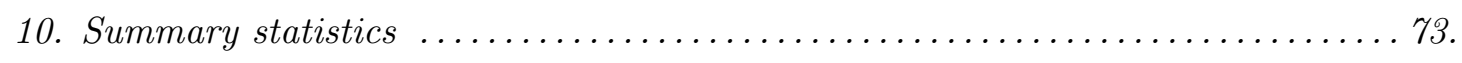

11. The effect of trade policies on skilled and unskilled workers ............... 74.

12. The effect of labor market flexibility on unemployment rate across less developed countries ................................................... 75 .

13. Trade policy and unemployment rate $(O L S$ and $I V) \ldots \ldots \ldots \ldots \ldots \ldots$.

14. Manufacturing sectors based on International Standard Industrial Classification

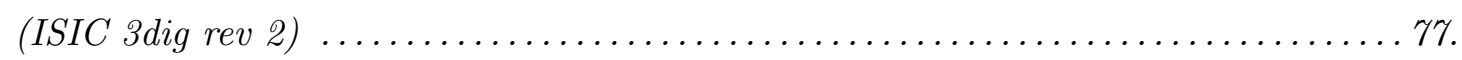




\section{ACKNOWLEDGMENTS}

I am grateful to my dissertation chair and advisor, Professor Peter Schaeffer, for his guidance and support during my doctoral studies. I was privileged to have Peter as my chair, his constant guidance and support made this dissertation possible.

I am immensely indebted to Professor Shuichiro Nishioka, whom I started with as my advisor at the initial stages of my doctoral research and continued with up to the completion of my doctoral studies. Shuichiro kindly offered me his valuable time during numerous discussion sessions and shared his invaluable knowledge on the subject matter. Without his informative criticisms and moral support this dissertation would not have been possible.

I thank my committee members; Prof. Tesfa Gebremedhin, Prof. Arabinda Basistha and Prof. Stratford Douglas for all their contributions. Their invaluable and insightful comments helped me to produce quality academic research work. I am very fortunate to have met Prof. Gebremedhin when I first joined West Virginia University, in our interactions I gained indispensable knowledge and experience. Prof. Gebremedhin offered me unprecedented support and guidance, during my entire graduate school life.

I owe my professional development to Prof. Clifford Hawley, chair of Economics Department at West Virginia University, for giving me the opportunity to teach several undergraduate courses. I was very lucky to have joined the college of Business and Economics at West Virginia University for my doctoral studies. It provided me with financial support and other resources, which helped me carry out quality research and develop teaching skills.

I am grateful to my friends and colleagues at graduate school, Eugene Bempong, Julie Lohi, Elena Bondarenko, Adam Pellillo and Jorida Papakroni. Those moments we shared at West Virginia University will forever be memorable.

Finally, I give special thanks to my Mom, Beatrice Karimi Mwilaria, and my wife, Linda Kimencu Mwenda, for their love, patience and moral support. 


\section{Chapter 1}

\section{STRUCTURE OF INDUSTRIAL SPECIALIZATION, VOLATILITY AND \\ LABOR MARKET FLEXIBILITY}

\subsection{Introduction}

The inexorable growth of world trade since the end of World War II generated enormous impetus towards understanding trade patterns and the underlying determinants of these patterns. To date, economists have assembled a rich theory that explains the structure of international trade and trade patterns that arise with increasing international exchange. The theory emphasizes differences in production capabilities due to technology, factor composition, firm heterogeneity, product differentiation and economies of scale. Alongside this mainstream theory of international trade, there is an emerging realization that institutions such as labor market flexibility, labor laws and regulations, property rights and other institutional structures influence patterns of international trade (Chor, 2010; Cunat and Melitz, 2009; Costinot, 2009; Levchenko, 2007; and Nunn, 2007). Empirical evidence, particularly on the role of labor market institutions in the determination of trade patterns, is limited. Theory suggests that labor flexibility confers comparative advantage. However, the linkages between flexibility of the labor market and industry characteristics such as, industry-specific volatility are not well understood. There is no consensus flexibility determines international export specialization and trade patterns.

The main objective of this paper is to empirically examine how flexibility of labor market influences exports specialization via interactions with industry level characteristics. I use an empirical model that is motivated, in part, by two theoretical models. The first model, due to Helpman and Itskhoki (2010), shows that flexibility of the labor market confers comparative advantage to the flexible economy, whereby a large share of export comes from differentiated industries. The second model, attributed to Cunat and Melitz (2009), asserts that flexibility of the labor market course comparative advantage for the flexible economy, whereby a large share of export comes from volatile industries. 
The two models affirm that labor market rigidity and flexibility course comparative advantages. However, the nature of specialization in the production that is coursed by the flexibility and rigidity of the labor market is not clear. Do flexibility of the labor market influence specialization in production towards volatile industries as indicated by Cunat and Melitz model? Or is the specialization towards capital-intensive industries or is it towards differentiated industries as Helpman and Itskhoki claims? An empirical study is necessary to tease out these issuing theoretical assertions in order to have a deeper insight on the linkages between labor flexibility and specialization of production. There are limited empirical and theoretical models that examine the links between labor market rigidity and flexibility, and trade patterns. Although many reasons could explain this state of literature, lack of good measures of labor market institutions and the correlation between labor institutions and production capabilities across countries are potential reasons why there are few studies that examine the role of labor institutions in the determination of trade patterns. For example, countries with better technologies and higher factor productivities tend to have better institutional structures. Such correlations could create a challenge for an empirical study that intends to examine the relationship between labor market institutions and the structure of international trade. However, there are indices that capture differences of labor market institutions across countries that are not necessarily correlated with countries income.

Botero et al. (2004) constructs indices that capture labor market rigidities fairly well and these indices show significant variation even across developed economies where production capabilities are significantly identical. I use three of these indices, Cost of adjusting hours worked index, Cost of firing workers index and dismissal regulations index to constructed a proxy measure of labor flexibility. ${ }^{1}$

\footnotetext{
${ }^{1}$ The labor flexibility measure is an average of all the three indices. A high value, (see rigidity of labor values reported on table 1) as constructed by Botero et al. (2004), indicate high rigidity of labor. I therefore, convert these values to capture increasing flexibility of labor by subtracting from 1, because the highest possible value is 1 , such that, a high value indicates low cost and thus more flexibility.
} 
The labor rigidity index reported on table 1 is an average of the three indices and it does not indicate any correlation with income across countries. Figures 1, 2 and 3 show insignificant correlation across for both developed and less developed.

\subsection{Flexibility of the Labor Market}

Botero, Djankov, La Porta, Lpez de Silanes and Shleifer (2004) have developed several indices to measure various labor regulations across many countries, both developed and less developed countries. I use three of those indices to developed a measure of labor flexibility and then examine how flexibility influences the structure of industrial specialization across many countries. The index capturing flexibility of labor is the average of; index capturing cost of adjusting hours worked, index capturing cost of firing workers, and an index for dismissal laws. These indices are constructed such that higher values corresponds to less flexibility, that is, higher resistance to the flow of workers. In estimating these indices BDLLS assumes a representative firm and worker, with some standard characteristics, in order to enable comparison across countries. ${ }^{2}$

1.2.1. Cost of adjusting hours worked: The cost of adjusting hours worked, is estimated using the maximum number of regular hours a representative employee works per year in each country. According to the estimates by the authors, these hours range from 1,758 in Denmark to 2,418 in Kenya. It is then assumed firms aim to increase hours worked from 1,758 to a maximum of 2,418 hours per year. For each firm, worked hours are increased to the countrys maximum, then the firm start adding overtime hours. In the case where, for example overtime hours are capped, such that employees cannot

\footnotetext{
${ }^{2}$ The representative worker is a full-time employee, who is not an executive and has worked for 20 years in the same firm. His salary plus benefits, during the whole period of employment, amount to the countrys GNP per worker. He has two children and the spouse only takes care of household cores with no other formal employment. This worker is a citizen of the country and belongs to the predominant race and religion/belief of the majority. The household resides in the most populous city in the country. The worker cannot be a member of labor union, unless the law makes it a mandatory requirement, and he retires at the age stipulated by the law. On the other hand the representative firm is a manufacturing firm that is fully owned by the citizens of the country and is located in the most populous city. It has 250 regular employees and it abides by all the stipulated laws and regulations but does not offer workers benefits and responsibilities other than those stated in the law. Vacations, holidays and overtime hours are excluded.
} 
accumulate worked hours to 2, 418 for the entire year, it is assumed the firm would double it workforce and pays each worker 1,758 hours. This also doubles the wage bill of the firm. The cost of adjusting hours worked is then estimated as the ratio of the final wage bill to the initial one.

1.2.2. Cost of firing workers: This variable captures the cost of firing 20 percent of the firms workers. Of the 20 percent, 10 percent are fired because they are redundant while the other 10 percent there is no reason given for firing. The cost of firing a worker includes the payments the firm makes before dismissing the worker. These include severance payment, and other mandatory penalties established by law or through collective bargain for a worker with three years of tenure with the firm. For illegal firing of a worker, the cost of firing is estimated as the annual wage of the worker. The new wage bill for the firm is the sum of the regular wage bill for the remaining workers plus the additional payments for dismissal. The cost of firing is then the ratio of the new wage bill to the initial wage bill.

1.2.3. Dismissal regulations: To capture dismissal regulations, BDLLS generates a variable that uses the average of seven binary variables. First, a dummy capturing a case whereby the firm is required to inform a third party before it can fire more than one worker. Second, a variable denoting a situation whereby the firm must get approval from a third party before it can dismiss more than one employee. A third dummy variable represents a requirement that the firm must notify a third party before a redundant worker is dismissed. A forth variable denotes the case whereby the firm must get approval from a third party in order to dismiss a redundant worker. The fifth variable captures the case whereby the firm must provide relocation or retraining alternatives prior to dismissal. The sixth dummy variable is equal to one if there are priority laws applying to dismissal or layoffs. Finally, the seventh binary variable captures priority regulations applying to reemployment. The employment index reported on Table 1, developed by Botero et al. (2004) based on the above described criteria, is used for empirical estimation in this paper to capture the flexibility of the labor market. 
1.2.4. Limitations of the labor flexibility index: This measure of labor flexibility is limited in that it cannot capture many factors that influence labor mobility within and between industries in a country. It assumes that the ease of reallocating labor within industries is mainly dependent on the costs associated with hiring, firing and adjustment in hours worked. For example a firm may have an incentive to retain highly productive workers by paying them higher wages regardless of the costs imposed in the labor market through various regulations and laws. The efficiency wage model, attributed to Shapiro and Stiglitz (1984), is a classic example that articulates the factors that motivate firms to pay wages above the market clearing wages. The labor index, however, has it's strength as a labor institution measure because it does indicate high correlation with income as is usually the case with many country-level measures of type of institutions.

\subsection{Export SPECIALIZATION PATTERNS}

Understanding the existing variations in export specialization patterns and how the nature of the labor market contributes to these specialization structures is vital for international trade policy, especially for countries that may want to expand and diversify exports. Export specialization patterns vary significantly across countries but the underlying factors that influence these patterns are not well understood. For example, according to Giovanni and Levchenko (2011) middle-income countries exports are highly concentrated in volatile industries while advanced countries exports are mainly in medium-risk sectors and fairly diversified. The authors find that among countries with safest export structures are some of the poorest and least diversified countries contrary to the notion that low-income countries tend to specialize in risky sectors such as mining and metals. Understanding the main determinants of these specialization patterns is the core purpose for this study.

The main contribution of this paper is to provide empirical evidence on how labor flexibility interacts with industry specific characteristics to influence export specialization. In particular, do countries whose labor markets are relatively flexible tend to specialize 
towards industries that exhibit high intrinsic volatility as suggested by theory? How does the structure of export specialization relate to differences in labor market flexibility across countries? This paper examines these questions using industry-level data for many countries and building upon the implications from the models by Cunat and Melitz (2009), and Helpman and Itshoki (2010).

\subsection{TheORETICAL FRAMEWORK}

The theory of comparative advantage suggests that countries will specialize towards their comparative advantage industries. I propose that if this specialization happens, then relatively flexible economies should specialize towards industries that exhibit high idiosyncratic volatility while rigid economies should specialize in relatively less volatile industries. Relatively flexible economies also tend to specialize away from capital-intensive industries because these industries do not benefit from rapid flow of workers across industries. This paper sheds light on these predictions by revealing that flexibility of the labor market influences export specialization away from industries exhibiting high intrinsic volatility and away from capital-intensive industries. Following Cunat and Melitz (2009), I present a conceptual framework that guides the empirical examination of the above hypothesis. I consider two countries, $F$ and $R$, with two different institutional scenarios, a flexible labor market and rigid one. In each country there are $L$ units of labor, which is not mobile across countries. The supply of labor is inelastic for any non-negative wage. Each country has a representative agent who consumes a continuum of finals goods whose consumption index is $Q$. Consumer preferences are assumed to be identical across countries. Agents maximize utility over a Cobb-Douglas aggregate $Q$ of a continuum of final goods.

$$
Q \equiv \exp \left\{\int_{6}^{1} \ln q(j) d j\right\}
$$


where $q(j)$ represents consumption of final good $j$. It requires a continuum of intermediate goods represented by $Z$ to produce the final good in each industry. The production function for each final good is therefore denoted as follows.

$$
y(j)=\left[\int_{0}^{1} y(j, z)^{\frac{\alpha-1}{\alpha}} d z\right]^{\frac{\alpha}{\alpha-1}}
$$

The above production function captures industrys technology in the production of a final good $j$. The consumption function, equation (1), and production function, equation (2), of the final good are denoted differently to emphasize that each industry is distinct in its production technology, represented by (2), within the country. Consumers however, consume a continuum of final goods across all industries. Industries production technologies vary within the country but not across the two countries. The term $y(j)$, equation (2) above, denotes production technology of industry $j$. Equation (2) also indicates that the final good in each industry is produced from a C.E.S. continuum of intermediate goods. The parameter $\alpha$ is greater than one, it captures elasticity of substitution between intermediate goods that are used to produce final goods. Labor is the only factor used in the production of each intermediate good, the production function is denoted by the following equation.

$$
y(j, z)=e^{\pi} L(j, z)
$$

where $\pi$ is a stochastic term, and within each industry $\pi$ 's are assumed to be random draws from a common distribution $\Phi_{j}($.$) . These \pi$ 's are independently identically distributed (iid) with a variance $\sigma^{2}(j)$, and vary across industries but are identical across countries. The variance $\sigma^{2}(j)$ captures the volatility of the industry $j$. This construction of volatility accentuates shocks to the intermediate goods producers. The term $\pi$, after it is realized, uniquely identifies the intermediate good producer $z$. It is therefore convenient to use $\pi$ as the index that represents intermediate goods.

In the flexible economy, $F$, markets are competitive with market forces of demand and supply determining the prices. The resources in this economy are allocated after 
the realization of $\pi$. The competitive nature of the flexible economy underscores the view that resources are easily reallocated towards their more efficient use at negligible cost.

In the rigid economy, markets exhibit less degree of competitiveness that characterize the flexible economy. In particular, wage $w_{R}$ is negotiated before the producer of intermediate goods can hire the workers. For example, labor unions could negotiate with the intermediate good producers and set a wage acceptable by both parties. The costs of adjusting labor and wage prohibit the firm from any adjustments after the workers have been hired. Essentially, producers of intermediate goods commit themselves to the costs of labor before the realization of $\pi$. This market scenario emphasizes a view that rigidities limits the firms from adjusting labor costs in response to changing market conditions. The rigidity of the labor market also ensures that intermediate good producers must pay all hired workers the agreed wage regardless of the realization of $\pi$. Moreover, in this labor market set up, changes in unemployment cannot pull down the economywide predetermined wage. The product and commodity market clears, subject to labor and wage constraints, in a competitive setting after $\pi$ has been realized.

In the flexible economy, without trade (autarky), profit maximization in the production of final goods leads to zero-profit condition denoted by the following equation.

$$
P_{F}(j)=\left[\int_{-\infty}^{\infty} p_{F}(j, \pi)^{1-\alpha} d \Phi_{j}(\pi)\right]^{\frac{1}{1-\alpha}}
$$

Profit maximization by intermediate good producer also ensures zero-profit condition. This leads to the following equation:

$$
P_{F}(j, \pi)=e^{-\pi} w_{F}
$$

where $w_{F}$ represents the equilibrium wage that is determined competitively before the realization of the shock. As mentioned earlier $\pi$ is used to index for intermediate goods since the productivity draw is specific to the intermediate good producer. Equations (4) and (5) yield the following expression: 


$$
P_{F}(j)=w_{F}\left(\frac{1}{\left[\int_{-\infty}^{\infty} e^{\pi(\alpha-1)} d \Phi_{j}(\pi)\right]^{\frac{1}{\alpha-1}}}\right)
$$

The denominator term in equation (6) captures productivity level in industry $j$. This productivity level is a weighted average of the productivity levels of the intermediate good producers $e^{\pi}$. It should also be noted that the weights relate to the intermediate goods cost share in the final good production. For the flexible economy, the productivity level of industry $j$ (the denominator term in equation (6)), can be written as follows:

$$
\theta_{F}(j)=\left[\int_{-\infty}^{\infty} e^{\pi(\alpha-1)} d \Phi_{j}(\pi)\right]^{\frac{1}{\alpha-1}}
$$

Given the zero-profit conditions, both the market for final goods and for the factor of production for these final goods clears in this flexible economy before trade takes place (autarky condition).

Turning to autarky conditions in the rigid economy, the firms maximize expected profit subject to input constraints. All firms in industry $j$ are assumed to be identical before the realization of $\pi$. The zero-profit condition for the production of final good $j$ imply that the price of the final good is equal to the cost of producing one unit. This is represented as follows:

$$
P_{R}(j)=\left[\int_{-\infty}^{\infty} P_{R}(j, \pi)^{1-\alpha} d \Phi_{j}(\pi)\right]^{\frac{1}{1-\alpha}}
$$

The zero-profit condition for the intermediate good producer implies that labor cost is equal to the expected revenue. This is represented as follows:

$$
w_{R} L_{R}(j)=\int_{-\infty}^{\infty} P_{R}(j, \pi) y_{R}(j, \pi) d \Phi_{j}(\pi)
$$


where $w_{R}$ captures the wage in the rigid economy. The market for intermediate goods then clears. This market clearing condition is captured by the following equation:

$$
e^{\pi} L_{R}(j)=\left[\frac{P_{R}(j, \pi)}{P_{R}(j)}\right]^{-\alpha} y_{R}(j)
$$

Equations (8), (9) and (10), (capturing the zero profit conditions in the production of the final goods, intermediate good producer and the market clearing condition respectively) leads to the following equation:

$$
P_{R}(j)=w_{R}\left(\frac{1}{\left[\int_{-\infty}^{\infty} e^{\pi \frac{\alpha-1}{\alpha}} d \Phi_{j}(\pi)\right]^{\frac{\alpha}{\alpha-1}}}\right)
$$

As in the case for the flexible economy, let the denominator of equation (11) be represented as follows:

$$
\theta_{R}(j)=\left[\int_{\infty}^{\infty} e^{\pi \frac{\alpha-1}{\alpha}} d \Phi_{j}(\pi)\right]^{\frac{\alpha}{\alpha-1}}
$$

Equation (12) captures the productivity level in industry $j$ for the rigid country. As noted above the two productivity levels, (7) and (12) are derived from autarky, zero-profit and market clearing conditions. In both economies productivity is a weighted average of productivity levels of the intermediate good producers. The distribution of these intermediate good productivity levels are the same in both countries, however, for each industry $j$, the productivity averages are different as the cost shares of the intermediate goods in the final good production vary across the two countries. Producers of final good in the flexible economy benefit from dispersion of productivity levels among intermediate good producers because they are able to efficiently shift their expenditures towards low priced intermediate goods. Efficient reallocation process is absent in the rigid economy as a result of existing barriers to flow of labor, which gives the flexible economy absolute advantage across all industries. Productivity levels can be represented using the following inequality, $\theta_{R}(j) \leq \theta_{F}(j)$ for all $j$. Whenever $\Phi_{R}(j)$ is non-degenerate (and there are idiosyncratic productivity shocks) then $\theta_{R}(j)<\theta_{F}(j)$. The preceding analysis 
is simplified by assuming normal distribution of productivity draws, a ranking of industries based on increasing volatility such that; standard deviation $\sigma(j)$ is increasing in $j$, and is differentiable and non-negative. Given these assumptions, industry productivity level in the flexible economy is presented as follows:

$$
\theta_{F}(j)=\exp \left\{(\alpha-1) \frac{\sigma^{2}(j)}{2}\right\}
$$

Under the same assumptions of normal distribution, the average industry productivity level for the rigid economy is presented as follows:

$$
\theta_{R}(j)=\exp \left\{\frac{\alpha-1}{\alpha} \frac{\sigma^{2}(j)}{2}\right\}
$$

Equation (13) and (14) represents average industry productivity levels for the flexible and rigid countries respectively under autarky: Consider now that the two economies are open for trade. Given that final goods are traded and intermediate goods cannot be traded between the countries, then equation (13) and (14) can be used to define relative productivity level in the sense described by Dornbusch et al. (1977) as follows:

$$
\frac{\theta_{R}(j)}{\theta_{F}(j)}=\exp \left\{-\sigma^{2}(j) \frac{(\alpha-1)^{2}}{2 \alpha}\right\}
$$

Let $X(j) \equiv \frac{\theta_{R}(j)}{\theta_{F}(j)}$ represent productivity differential, from equation (15) above. Then the case that $X(j) \leq 1$ is consistent with the fact that labor market flexibility confers absolute advantage to the flexible economy. In addition labor market institutions interact with industry volatility to generate a pattern of Ricardian type comparative advantage. It is the case that when there are no shocks, differences in labor market flexibility are irrelevant because there is then no source of comparative advantage, no motive for trade and no specialization. However, in the presence of firm-level shocks, the flexible economy can reallocate labor across firms more easily leading to increased productivity across industries relative to the rigid economy. 


\subsection{Industry-Specific Volatility}

Empirical literature on trade openness and volatility has mainly focused on identifying the sources of macroeconomic volatility and establishing the relationship between volatility, trade openness and economic developments. For example, Koren and Tenreyro (2007) find that countries with relatively large share of production concentrated in industries that exhibit high intrinsic volatility tend to experience higher aggregate volatility, which substantially impacts macroeconomic variables. Other empirical studies on volatility and trade (See Easterly et al 2001, Imbs 2007, Laursen and Mahajan 2005, and Giovanni and Levchenko 2009) examine the effects of overall volatility of the aggregate output growth on various macroeconomic variables.

In particular, Giovanni and Levchenko (2009) argue that overall trade relates to overall volatility via the variance of each industry, $\sigma_{j}^{2}$, the covariance properties between industries, $\sigma_{j k}$ or through the production structure of the economy, $a_{j}$. The authors estimate aggregate volatility as follows:

$$
\sigma_{A}^{2}=\sum_{j} a_{j}^{2} \sigma_{j}^{2}+\sum_{j} \sum_{k \neq j} a_{j} a_{k} \sigma_{j k}
$$

An important focus, in this paper, is to estimate values that capture industry-specific shocks. These values are then used to proxy for the industry-specific volatility variable. Following Giovanni and Levchenko (2011), I estimate industry-specific shock using industry-level value added. Note that the aggregate volatility is not the variable of interest, as the case in Giovanni and Levchenko, but one of the components that form the aggregate country volatility, the global industry-specific shock. This is the component of the shock that is specific to the industry, which I estimate using the deviations in growth rate of value added. Letting $g_{c u t}$ to denote deviation to growth in value added in country $c$, industry $j$ and at time $t$, then the global industry-specific shock, $v_{j t}$ is estimated as the cross-country average of $g_{c j t}$ in each of the industries. 
Table 3 indicates values of standard deviation and variance, estimated by Giovanni and Levchenko (2011), which are used to proxy for global industry-specific shock. These values suggest that the most volatile industries are mining, petroleum and coal products, and non-ferrous metals. While food products, beverages, wearing apparel, and machinery electrical are the least volatile. The values estimated by the authors may differ from those I estimated on table 4. The fact that Giovanni and Levchenko use a different data set for a different time period and industry-level value added per worker could explain the variation of their estimation from those in table 4. Value-added per worker is normally stable and thus may not capture industry-specific volatility effectively.

In my estimation I use year differenced log of value added. Annual industry-level value added is used and not value added per worker used by Koren and Tenreyro (2007), and Giovanni and Levchenko (2011). A complete description on how volatility variable is constructed in this paper is presented under subsection 5.2.

In the Cunat and Melitz model volatility is high if the industry has large share of volatile firms. Essentially industry volatility, in the Cunat and Melitz model, is derived from firm-level volatility. Volatility of the industry would be captured better by estimating the volatility of the firms that form the industry, however its practically challenging task because firm-level data are rarely available across many industries and countries.

\subsection{Empirical Strategy and Data}

To examine the pattern of specialization I use a dataset compiled by Nicita and Olarreaga (2006) on trade and production. The dataset covers the period 1990 to 2002 for most industries and countries. This dataset is disaggregated into 28 manufacturing industries across 68 countries. It includes annual data on trade flows (exports and imports) and production variables such as employment, output and value-added. The data are averaged over the period 1990-2002 to smooth out fluctuations. Exports (value of export adjusted to international constant prices) are used to estimate revealed comparative advantage $(\mathrm{RCA})$ values for all industries across countries. RCA values are used to capture 
export specialization. Higher values of RCA indicate a higher degree of specialization in that industry. Industry-level RCA is used as the response variable. Explanatory variables of interest are industry-specific volatility and labor market flexibility.

To measure labor market flexibility across countries I use rigidity of employment index, which is an average of three indices (cost of hiring index, cost of firing and rigidity of work hours) developed by Botero et al. (2004). This index captures important crosscountry differences in the flow of workers and jobs across occupations. It also captures differences in the flow of workers in and out of employment. The most recent data on rigidity of employment index is from World Bank Development Indicators website for the year 2008 and 2009. It is assumed labor market flexibility is institutional in nature (capturing differences in labor market institutions across countries), and according to North (1991) institutions are sticky, meaning they only change very gradually over many years. The view by North that institutions change very gradually over several decades supports my use of these most recent data on rigidity of employment even though other variable in this empirical analysis span over 1990 to 2002.

In addition to the main variables of interest namely, measure of export specialization, measure of industry volatility and measure of flexibility, I include an interactions control variable that potentially influence structure of specialization. The interaction between industry level capital-intensity and capital-abundance may potentially influence export specialization. Capital intensity for each industry is calculated as the gross fixed capital formation divided by the number of employees in the industry. And capital abundance for each country is calculated as countrys gross fixed capital formation divided by the total adult population. Country-level data are obtained from the World Bank Development Indicators website and the Penn World Tables (PTW 7.0) while industry-level variables are obtained from the Nicita and Olarreaga (2006) Trade Protection and Production dataset available on the World Banks website.

1.6.1. Industry Specialization. Trade economists have rested on a less disputed view that comparative advantage is an important determinant of the commodity composition 
of trade. As a result of this overriding importance of the principle of comparative advantage in international trade theory, use of empirical measures of comparative advantage is necessary in empirical studies that attempt to understand the pattern of goods imported and exported. Economists develop realistic indices that are based on observed variables to conjecture what would be the form of autarky relative prices. These indices are used in practical work to measure the structure of specialization. For this study revealed comparative advantage (RCA) values are calculated, using real value of exports at industry level, to infer export specialization. RCA values vary across industries within the country and also across countries.

I use the value of exports to estimate RCA for all 28 manufacturing industries across 68 countries. To smooth out any annual fluctuations, exports are averaged over the period 1990-2002. Comparative advantage formulation, attributed to Balassa (1965) is used to estimate revealed comparative advantage for all manufacturing industries across all the countries as follows:

$$
R C A_{c j}=\frac{x_{c}^{j} / \sum_{j} x_{c}^{j}}{\sum_{c} x_{c}^{j} / \sum_{c} \sum_{j} x_{c}^{j}}
$$

where $x_{c}^{j}$ denotes the value of export, superscript $j$ denotes industry and subscript $c$ represents country. The term, $\sum_{c} x_{c}^{j}$, denotes the sum of export for industry $j$ across all countries in the sample, while $\sum_{j} x_{c}^{j}$ represents the sum of export across industries. The term, $\sum_{c} \sum_{j} x^{j} c$, denotes the global total value of export for all industries and countries in the sample.

RCA value above unit suggests a country has a comparative advantage in that industry and thus specialize in that industry. When RCA value is below 1, it indicates comparative disadvantage in that industry and thus specialization towards that industry is muted. Moreover, RCA values in table 2 can be used to imply similarities among industries in which a country has a revealed comparative advantage and thereby also indicate the characteristics of a country that would give rise to its comparative advantage. For example, it can be inferred that Austria specialize relatively more towards Wood 
and Cork products, Paper products, Furniture and Fixtures, Printing and Beverage industries among other industries. The Czech Republic specializes towards industries such as, Tobacco, Textiles, Rubber products and fabricated metal among other industries.

1.6.2. Estimating industry-specific volatility. Volatility variable is constructed using annual industry-level data on value added. If $g_{c j t}$ represents deviations, from the average, of the value added in country $c$, industry $j$, and at time $t$, then the global industry-specific volatility $\left(v_{j t}\right)$ is estimated as the cross-country average of $g_{c j t}$ in each of the industries as shown in the following equation:

$$
v_{j t}=\frac{1}{C} \sum_{c=1}^{C}\left(g_{c j t}\right)
$$

The term, $g_{c u t}$, is estimated as the year-differenced log of industry-level value added, which captures the standard deviation of the annual growth rate of industry value added. The values reported on table 4 are $v_{j t}$, averaged over the time period, for each industry. These values indicates that tobacco, other chemical products other than industrial chemicals, and plastic products are the most volatile manufacturing industries. The least volatile industries are textile, industrial chemicals and transport. I use these values to proxy for industry-level volatility. The interaction between this measure of industry volatility and labor market flexibility play a role in the determination of export specialization.

\subsection{EMPIRICAL MODEL}

The model specified, interacts industry-level and country level variables and controls for industry and country fixed effects. The objective is to examine the partial effects of these interactions on the degree of export specialization.

$$
R C A_{c j}=\alpha_{0}+\alpha_{1}\left(V O L_{j} * F L E X_{c}\right)+\alpha_{2}\left(K_{c j} * F L E X_{c}\right)+\alpha_{3}\left(K_{c j} * K_{c}\right)+\epsilon_{c j}
$$


where $R C A_{c j}=\frac{x_{c}^{j} / \sum_{j} x_{c}^{j}}{\sum_{c} x_{c}^{j} / \sum_{c} \sum_{j} x_{c}^{j}}$ denotes a measure of the degree of export specialization. Variable $X_{c}^{j}$ denotes the value of exports industry $j$ in country $c$. Industry-level volatility is captured by the term $V O L_{j}$, and the flexibility of the labor market is denoted by $F L E X_{c}$. The variable $K_{c j}$ denotes industry-level capital intensity while $K_{c}$ represents country-level capital abundance.

The model predicts a positive estimated coefficient, $\alpha_{1}$, which imply that more flexibility of the labor market influences specialization towards more volatile industries. After controlling for volatility across industries it is predicted the value of $\alpha_{2}$ (estimated coefficient on the second interaction variable) would be negative, which means rigidity or less flexibility of the labor market influences specialization towards capital-intensive industries. Estimated coefficient, $\alpha_{3}$, on the last interaction variable is expected to be positive, which means increasing capital influences export specialization towards capital-intensive industries. There are possible industry-specific factors and country-specific characteristics that are likely to affect the structure of specialization, but are not captured by explanatory variables in the model. The model therefore, controls for Industry and country specific effects.

1.7.1. A Probit estimation: The response variable, $R C A$, in the model is first constructed as a continuous variable whereby increasing values capture an increasing degree of specialization. The probit estimation is used in the second case whereby $R C A$ variable is constructed as a binary variable with ones and zeros. $R C A$ values greater than or equal to unit are replaced with ones and these capture comparative advantage industries. The theory of comparative advantage assumes that countries tend to specialize towards comparative advantage industries. On the other hand values below unit are converted to zeros, these capture comparative disadvantage industries and countries tend not to specialize toward these industries. Taking $R C A$ values equal to or above unit to capture comparative advantage industries and values below unit to capture comparative disadvantage industries is consistent with Balassas (1965) formulation of revealed comparative advantage estimation. 


\subsection{Results And Discussion}

Estimated results from the empirical model are presented on tables 5 and 6 . Column 2 , on table 5 , shows coefficient estimates and robust standard errors with industry fixed effects. The estimated coefficient on the first interaction $(V O L * F L E X)$ is statistically significant and has positive sign. The positive sign implies that as the labor market becomes more flexible, holding other factors constant, the country tends to specialize towards industries that exhibit high volatility of value added. For example, 1 percent change of labor flexibility increases the degree of specialization towards volatile industries by about half of a percentage.

This empirical evidence indicates that a country could potentially expand it's export composition by making labor more flexible, for example by eliminating excessive labor laws and regulations. This could enable a country to increase export in industries that experience intrinsic volatility in value addition.

The estimated parameter on the second interaction variable $(K * F L E X)$ has negative sign and is statistically significant implying, after controlling for the effects of volatility, flexibility of the labor market encourages specialization towards less capital intensive industries.

As predicted by the model, the sign on the interaction variable $K_{c j} * K_{c}$ is positive and significant. It is interpreted that, after controlling for flexibility and volatility, a capital abundant country tends to specialize towards capital-intensive industries.

Table 6 presents results from probit estimation. In this estimation a negative regression coefficient means that the explanatory variable increases the probability of the outcome. In the case for the interaction between volatility and labor flexibility, the estimated value is negative and statistically significant at one percent confidence level. This means higher flexibility diminishes the probability that a country will specialize towards industries exhibiting high intrinsic volatility. A large regression coefficient means the explanatory variable strongly influences the probability of that outcome. 


\subsection{Concluding Remarks}

This study finds that the flexibility of the labor market influences the patterns and structure of global trades. The flexibility of labor, in this study, is narrowly defined as average costs of hiring, firing and ease of adjusting hours worked for a representative employee in an industry. These costs are believed to influence the flow of labor within and between industries. If these costs are low, labor can easily reallocate in the presence of production or demand shocks.

A country whose labor market is more flexible tend to concentrate significant exports in industries exhibiting high fluctuations in value added and industries that are less capital-intensive. The main implication of the finding is that policies that influence the flow of workers and jobs across industries could potentially affects the patterns and structure of export specialization. For example, countries that intend to expand export industries could benefit by implementing policies that make their labor markets more flexible. These policies may include better employment contracts, reduced powers of labor unions and other policies that minimize rigidities in the labor market. 


\section{Chapter 2}

\section{Trade Protection and Industry-SPecific Volatility}

\subsection{INTRODUCTION}

Global trade has increased significantly in the last half century. The conventional view is that this trend is mainly attributed to systematic reductions in trade restrictions during the same period. The gradual reduction of trade barriers has increased market accessibility and integrated markets for goods, services and capital, but also created concerns that the resulting openness propagates macroeconomic volatility. A burgeoning body of literature that links openness to volatility of various macroeconomic variables tends to insinuate that openness contributes to volatility. Easterly, Islam and Stiglitz (2001) suggest a positive partial correlation between openness and growth volatility. Rodrik (1997) argue that volatility in the labor market, volatility in hours worked and earning, is correlated with openness. Kose, Prasad and Terrones (2003) find that openness correlates with volatility of output growth. Di Giovanni and Levchenko (2009) find that a measure of openness to international trade is positively associated with sector volatility (measured by the log variance of the annual growth rate of output per worker in the sector). Di Giovanni and Levchenko also assert that more trade in a sector mutes aggregate output volatility. But openness creates specialization, which work to minimize volatility. Bekaert, Harvey, and Lundbald (2006) argue that openness of financial markets is negatively related to the consumption growth volatility. The links, between trade openness and volatility, identified in the literature do not have solid theoretical foundation; they are multifaceted views pointing to openness of the financial capital markets and trade in goods and services as potential sources of macroeconomic volatility. There is no clear consensus on the source of macroeconomic volatility, and the nature of the relationship between trade openness and volatility of various macroeconomic variables is not well understood, which leaves this relationship an open question subject to empirical examination. This paper attempts to fill the existing gap by examining the link between 
trade barriers and industry-level volatility. I employ an elaborate theory of endogenous trade-policy determination to develop and empirical model that explain the effects, on trade barriers, of industry-level volatility and other industry-level factors. The empirical model is based on the premise that openness to international trade arise from deliberate actions taken by policymakers as they respond to the demands of special interest groups (industries), who stands to gain from more or less open international markets. On one hand, industries exhibiting high volatility demand protection from policymakers thus limiting openness in these industries. Industry-level volatility therefore limits trade openness if politicians provide demanded protection to these volatile industries. On the other hand, industry-specific volatility interact with labor flexibility to generate some form of comparative advantage in the country with flexible labor market. This is the kind of comparative advantage explained by Grossman and Itskhoki (2010), and Cunat and Melitz (2009). The effects on protection of these interactions are negative because comparative advantage industries tend to demand less trade barriers leading to more open international markets. These views are analyzed in this paper.

\subsection{Determination of Trade Barriers}

Recent decades have experienced unprecedented reductions in barriers to commodity and commercial services trade across countries. Average tariff rates across countries are lower than any other time in history and the gains, resulting from increases in cross border flow of goods, commercial services and capital due to lower barriers, are indisputable. In part, coordinated international trade policies through bilateral and multilateral initiatives, usually guided by the World Trade Organization (WTO) and its predecessor, the General Agreement on Tariffs and Trade (GATT), are credited for this greater openness to international trade. Despite these monumental changes in the global trading system protectionism is still a global concern. Countries have maintained restrictive trade policies across industries that are considered politically important. Developed countries, 
such as United States, that have managed to lower average tariffs significantly maintain restrictive trade barriers, in form of subsidies, in the agricultural sector. Average tariff rates across less developed countries are relatively high compared to the average tariff rates in developed countries. As witnessed from the breakdown of the Doha trade negotiations in the summer of 2010, the issue of protectionisms is as important today as it was a few decades ago. For example, in recently years when many countries were worried about declines in macroeconomic variables such as employment and real output, the public debate seemed to favor protectionism.

Trade barriers are considered, for most part, detrimental to global economic development. The premise behind this view is that barriers, such as tariffs, quotas, and non-tariff barriers, course inefficiencies and reduced welfare because they distort prices. Most economists subscribe to the view that trade barriers need to be eliminated because a more open global economy, one without restrictions on the flow of goods and services, is better for economic development. In reality however, almost every country imposes some form of trade barriers and trade regulations that are meant to limit access to international markets. What are the determinants of these industry-specific trade barriers and regulations? Economists have proposed numerous models in an effort to answer this question. For example, models by Krugman (1987), and Grossman and Helpman (1991) articulate how tariffs could increase welfare when they target specific industries. The authors show per capital gross domestic product could increase when tariffs or quotas targets those industries that course externalities. Some existing trade barriers, in specific industries, could be result of informed policies meant to maximize gains in those industries that course externalities. Other models such as protection for sale model due to Grossman and Helpman suggest that trade barriers could be imposed, regardless of the implication to the overall welfare, through a competitive political process where gains concentrate on few organized special interest.

Theoretical models that explain how trade barriers and overall trade policies are determined are extensive (see Gawande, 2003). However, empirical studies are limited. 
The prevailing low average tariff rates across most developed countries could explain the inertia towards empirical studies that relates to determinants of trade barriers and overall trade policy. However, recent developments in the field of international trade seem to change the state of empirical literature on trade policy. First, greater concentration, by trade economists, on industry and firm level productivities to explain changing patterns in international flow of goods and services has generated interest to understand the structure of tariffs at industry level. A good example of this renewed focus on tariffs is the work by Nunn and Trefler (2010). The authors assert that the structure of tariffs across industries is important for economic policy because targeted tariffs influences longterm economic growth. The second recent developed that seem to have renewed interest in the study of trade barriers is the great recession of 2008-2009. Bown (2011) points the collapse of trade flows during the 2008-2009 recession raised concerns on the possible reemergence of protectionist policies. The 2008-2009 great collapse in international trade revived debates on temporary trade protection to mitigate the effects of the recession.

In the political and public discourse there is evidence of a renewed focus on trade restriction. For example, Paul Krugman wrote on the New York Times in February 2009:

"The economic case against protectionism is that it distorts incentives: each country produces goods in which it has comparative disadvantage, and consumes too little of imported goods. And under normal conditions that is the end of the story. But these are not normal conditions..."

It suffice to say that the changing global trading systems and the accruing knowledge on the importance of firm and industry level production structures in the determination of trade flows and patterns, emphasize the need for a deeper understanding, at industry level, of the determinants of trade barriers. 


\subsection{International Trade and Volatility}

Di Giovanni and Levchenko (2009) present three linkages between aggregate volatility and trade openness. The authors find a positive correlation between exposure to international trade and volatility of output growth at industry level. They also point out that more trade in a sector, whose growth is less correlated with aggregate growth, decreases aggregate volatility. And finally, they assert that more trade in a country leads to greater specialization, which could lead to increased volatility. These findings are important steps towards answering a broader question on the sources of macroeconomic volatility. However, they do not inform how industry specific-volatility could affects openness via trade policies that target volatile industries. In addition, openness (computed as exports plus imports divided by output) and volatility are positively related for some industries and negative for other industries. Figure 1 indicates correlations of openness and volatility at industry level. The industries are defined according to the International industrial classification (ISIC). The scatter plots on the top row of figure 1, beginning from left, represents Tobacco manufactures and Manufacture of footwear, except vulcanized rubber or plastic footwear. The bottom row, from left, represents manufacture of mineral products and Manufacture of pottery, china and earthware. The negative relationship between openness and volatility for all four industries could imply that volatility of the industry reduces openness to trade. However, the scatter pots are not sufficient to infer causality. Figure 2 denotes the scatter plots for tariffs and volatility. The upper panel, from top left, indicate positive correlation between tariffs and volatility for three industries; Tobacco manufactures, Manufacture of paper and papers products, and Manufacture of machinery and pottery. Lower panel show both positive and negative relationships for other three industries. These findings farther justify a need for through empirical analysis to understand the relationships between openness to trade and volatility. The theory and empirical analysis under section 4 and 5 aims at establishing the direction of causality between trade barriers (hindrances to openness) and volatility. 


\subsection{Theoretical Framework}

Previous theoretical developments attempted to determine common economic and political determinants of trade barriers across countries and industries. Underlying these theories is the notion that trade barriers could create inefficiencies and lower welfare of a society. Therefore trade barriers are better explained by political motive rather than economic efficiency motive. Although there are variations of theoretical models on the determination of trade policy, a common view that emerges is that forces of demand and supply determine equilibrium level of protection. Interest groups demand protection by acting rationally (comparing marginal costs and benefits of lobbying for protection) and politicians (policy-makers) supply this protection as they seek to maximize personal objectives (self-interested objectives could include re-election among others). ${ }^{1}$ The idea of viewing political motives as the main determinants of trade policy is well articulated by the "protection-for-sale" model due to Grossman and Helpman (1994) and its variations that are surveyed by Gawande and Krishna (2003). In particular, Grossman and Helpman model builds an elegant conceptual framework that over the years has enabled economists to understand why we observe restrictive trade policies even with the compelling arguments on the benefits of unrestricted trade. Since the model of protection-for-sale is the most compelling recent theoretical foundation upon which many other theories and empirical studies on endogenous trade policy are anchored, I present a brief review of protection-for-sale model from Feenstra (2003, chapter 9, pp.305-309).

Consider an economy with $M$ goods and a numeraire export good. All $M$ goods and the numeraire good are additively separable in utility. Consumers maximize the following quasi-linear utility function:

\footnotetext{
${ }^{1}$ The main contributions on the endogenous trade policy literature are by: Brock and Magee (1978); Findlay and Wellisz (1982); Hilman (1982, 1989); Baldwin (1985); Magee, Brock and Young (1989); Trefler (1993); Grossman and Helpman (1994); Helpman (1995); Lee and Swagel (1997)
} 


$$
U=\sum_{j=1}^{M} u_{j}\left(q_{j}^{c}\right)+q_{0}^{c}
$$

where $q_{j}^{c}$ denotes consumption of good $j=1, \ldots, M$ and the superscript $c$ captures the consumer. Consumers are equal to the number of workers, denoted by $L$, for the entire economy. The term $q_{0}^{c}$ captures the consumption of numeraire export-good and the indirect utility function of the individual consumer is given as follows:

$$
v\left(p, \omega^{c}\right)=\sum_{j=1}^{M} u_{j}\left[d_{j}\left(p_{j}\right)\right]-p^{\prime} d(p)+\omega^{c}
$$

where $p$ denotes a vector of prices, $\omega^{c}$ is the income of the consumer, $d_{j}\left(p_{j}\right)$ represents consumption in terms of the price. The first two terms on the right hand side of equation (20), captures the consumer surplus. Let this consumer surplus per person be denoted by following:

$$
X(p)=\sum_{j=1}^{M} u_{j}\left[d_{j}\left(p_{j}\right)\right]-p^{\prime} d(p)
$$

From equation (20) and (21), the individual consumer welfare can be written as follows:

$$
v^{c}\left(p, \omega^{c}\right)=X(p)+\omega^{c}
$$

On the production side, production technology for each industry $j=1, \ldots, M$ is denoted by the following equation. $y_{j}=f_{j}\left(L_{j}, K_{j}\right)$, where $y_{j}$ denotes the output, $L_{j}$ is the labor input and $K_{j}$ represents the capital. The capital input is specific to the sector and one unit of labor produces the numeraire commodity, which implies the wages are fixed at unity. The profit gained from each additional unit of the specific input is denoted by the following equation:

$$
\pi_{j}\left(p_{j}\right)=\max \left[p_{j} f_{j}\left(L_{j}, K_{j}\right)-L_{j}\right]
$$


Optimal outputs are determined using the profit equation (5). In each industry the optimal outputs are denoted by the following expression:

$$
\pi^{\prime} j\left(p_{j}\right)=y_{j}\left(p_{j}\right)
$$

Import industry receives a positive tariff $\tau$ on foreign good. The imports for each good are given by the following equation:

$$
z_{j}\left(p_{j}\right)=L\left[d_{j}\left(p_{j}\right)\right]-y_{j}\left(p_{j}\right)
$$

The revenue collected by the government from the imposed tariff is denoted by the following equation:

$$
R(p)=\sum_{j}^{M} z_{j}\left(p_{j}\right)\left[p_{j}-p_{j}^{*}\right]
$$

where $R(p)$ represents tariff revenue, $z_{j}\left(p_{j}\right)$ captures the imports and $p_{j}^{*}$ captures fixed foreign price.

Assuming that a section of the population earns; returns (from the specific capital they own in each industry), wages (from the unit labor they provide), share distributed tariff revenue and consumer surplus, then welfare of owners of specific capital in industry $j$ is given as follows:

$$
E_{j}(p)=\pi_{j}\left(p_{j}\right)+A_{j}[X(p)+1]+\frac{A_{j}}{L} R(p), j=1, \ldots, M
$$

where $E_{j}(p)$ represents the sum of welfare by the owners of specific capital in industry $j$. The term $A_{j}$ denotes the population that own specific capital. There are $(L-A) \geq 0$ individuals who do not own capital but supplies labor. The term $A=\sum_{j=1}^{M} A_{j}$ represents all individuals who own specific capital and $L$ represents the total population. The welfare of these individuals comes from the wages, consumer surplus and share of the distributed tariff revenue. This welfare is give as follow:

$$
E_{0}(p)=\left[1-\frac{A}{L}\right] R(p)+(L-A)[1+X(p)]
$$


The total welfare is obtained by using equation (9) and (10), and summing them over industries and the working population. The total welfare is represented by the following expression:

$$
E(p)=L[1+X(p)]+R(p)+\sum_{j=0}^{M} E_{j}(p)+\sum_{j=1}^{M} \pi_{j}\left(p_{j}\right)
$$

Grossman and Helpman (1994) model (G-H model henceforth) assume that, some industries $s \in S_{0}$ are organized lobbies, and $s \in S_{u}$ are unorganized lobbies. Each lobby aims to influence trade policy through contributions to the electoral processes. The elected policymakers (the government) formulate trade policy by weighing lobbies contributions against the welfare of the society. They then impose tariffs that maximize the following welfare function:

$$
Q(p)=\gamma E_{s}(p)+\sum_{s \in S_{0}} D_{s}(p)
$$

where $D_{s}(p)$ represents industries' contribution plan for the electoral processes given the price vector $p_{j}=p_{j}^{*}+\tau_{j}$ that they face in the market. In this case it is assumed that expression (31) holds.

$$
D_{s}(p)=\max \left\{0, E_{s}(p)-B_{s}\right\}, s \in S_{0}
$$

The G-H model assumes that the societies welfare (first term on the right hand side of equation 12) is weighted by a positive weight $\gamma$. Following Bernheim and Whinston (1986), the governments welfare function (equation, 30) can be written as follows:

$$
Q(p)=\sum_{s \notin S_{0}} \gamma E_{s}(p)+\sum_{s \in S_{0}}\left[(1+\gamma) E_{s}(p)-B_{s}\right]
$$

Equation (14) represents a government welfare function that gives different weights to the welfare of the organized lobbies from that of the unorganized lobbies. G-H model shows that the link between the equilibrium tariffs and the underling determinants can be established by maximizing (14). The steps required to solve the maximization problem, involve taking derivatives of the welfare functions for the organized and unorganized industry, and for workers, and then computing first-order conditions. These steps gives the 
following equation for equilibrium tariffs as a function of the underlying determinants:

$$
\frac{\tau_{s}}{p_{s}}=-\left(\frac{p_{s}}{z_{s}} \frac{\partial z_{s}}{\partial p_{s}}\right)^{-1}\left(\frac{\eta_{s}-\lambda}{\gamma+\lambda}\right)\left(\frac{y_{s}}{z_{s}}\right)
$$

where $\frac{y_{s}}{z_{s}}$ represents the fraction of domestic production to imports, $\eta_{s}$ is an indicator variable that takes a value of one for organized industries $s$ and zero otherwise, $\lambda_{0}=$ $\sum_{s \in S_{0}}\left(\frac{A_{s}}{L}\right)$ captures the fraction of the population that own a specific factor in an organized industry. The G-H model precisely links the size of import tariffs to the ratio of domestic production to import and the inverse of import demand elasticity. The model provides, in part, an elaborate theoretical foundation upon which my empirical analysis is anchored. Taking natural logs on equation (33) gives the following expression:

$$
T=X_{1}+X_{2}+X_{3}
$$

where $T$ denotes the natural $\log$ of $\left(\frac{\tau_{s}}{p_{s}}\right)$. The terms on the right hand side of equation (16), $X_{1}, X_{2}$ and $X_{3}$, respectively, represent $\ln \left(\frac{z_{s} \partial p_{s}}{p_{s} \partial z_{s}}\right), \ln \left(\frac{\eta_{s}-\lambda_{0}}{\gamma+\lambda_{0}}\right)$ and $\ln \left(\frac{y_{s}}{z_{s}}\right)$.

The novelty of this paper is the underlying link between the term $X_{1}$ and industry volatility. The higher the industry volatility the higher the term $X_{1}$ will be. The intuition behind this relationship is based on the view that prices will be more responsive to small changes in imports in industries that are highly volatile. In the preceding empirical analysis, I employ a measure of industry volatility to capture this price sensitivity to changes in imports. The term $X_{2}$ is captured by a measure of industry comparative advantage, the interaction variable between volatility and flexibility of the labor market. The term $X_{3}$ is captured by a measure of import penetration and other variables are introduced into the empirical model to control for other possible determinants of trade barriers.

Trefler (1993) argues that comparative advantage factors are important determinants of trade protection. His analysis of the impact of non-tariff barriers on the U.S. imports, that exploits endogenous trade policy theory, provide insight on various factors that explain trade barriers. He uses a simultaneous tobit model to examine the effects of 
eliminating trade barriers between U.S. and Canada. Although, he finds measures that capture labor market rigidities (labor union, employment size, tenure and geographical concentration) are not significant in determining non-tariff barriers across U.S. industries, it is worthwhile to investigate if labor market rigidity is an important variable using data for many countries. Treflers finding is a special case for the U.S. because data across countries indicates that labor market institutional measures are important determinants of trade barriers. Given that debates in both public and political arenas relates to labor market issues due to job losses in the import-competing industries, one would expect those affected by high import penetration would lobby for trade policies that protect their interests. I find evidence, using industry-level data across many countries (both developed and developing countries), that the interaction between labor market institution (measured by the flexibility of the labor market) and industry specific characteristic (such as industry-specific volatility) partially explain a significant variation in trade protection.

\subsection{Empirical Strategy and Model Specification}

I estimate a model of trade protection that relies on protection-for-sale and other related theoretical and empirical extensions. ${ }^{2}$ Trade policy is determined based on underlying industry-level factors and industries political influence. In this model the response variable (trade protection or trade policy) is measured by industry-level tariffs and the determinants of trade protection are used as explanatory variables.

\subsubsection{Variables capturing demand for protection.}

2.5.1.1. Industry volatility: There are two links through which industry-level volatility influences trade protection. First, industries that exhibit high intrinsic volatility tend to be prone to shocks that exacerbate fluctuations of output and income. As a result, agents associated with these industries demand protection from policy-makers. Policy-makers

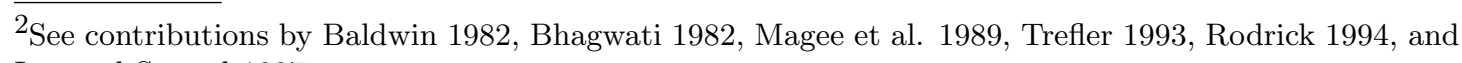
Lee and Swagel 1997. 
supply demanded protection to satisfy personal interests, and since it is not easy to reverse such policies after implementation, protection in volatile industry remain relatively high over time. Second, volatility may influence trade protection from a comparative advantage perspective whereby volatility interacts with flexibility of the labor market. This interaction is explained below under comparative advantage variables.

2.5.1.2. Import penetration: Import penetration is defined as gross import divided by domestic consumption. Domestic consumption is calculated as the sum of domestic production and net imports. Endogenous trade policy theory predicts private domestic agents respond to higher import competition by intensifying their lobbying for protection. Essentially demand for protection rises when industry is increasingly facing import competition. Policy makers respond by supplying protection to maximize their political gains.

2.5.1.3. Share of industry export in gross output: Agents associated with industries that serve both domestic and international market may hesitate to lobby for protection fearing retaliation. If export share of their production is significantly high then agents weigh gains from protecting domestic market and potential loss of the export market if the trading partners retaliate.

\subsubsection{Comparative advantage variables.}

2.5.2.1. Interaction of volatility and labor flexibility: If labor market is flexible then it is expected volatile industries will have relatively less protection because flexibility confers comparative advantage in volatile industries. Volatility interacts with labor flexibility to course a Ricardian type of comparative advantage in the sense articulated by Cunat and Melitz (2009). Labor market flexibility in this case refers to the ease of reallocation of workers and jobs within industries in a country. Di Tella and MacCulloch (2005) assert that labor regulations that increase the costs of hiring and firing, as well as generous welfare state that protects the unemployed are behind the differential labor market performances, for example, within the OECD. The World Bank data on labor market 
flexibility show that within OECD most of the continental Europe has more rigid labor market compared to North America, the British Isles and Oceania. Labor market flexibility varies both across developed and developing countries. Two views emerge from a quick survey of the broad literature on labor market flexibility. One relates to the adjustment of the labor market to periodic shocks and this adjustment is realized via a combination of adjustments in wages, labor supply and labor demand. This process of adjustment in the presence of shocks involves rapid reallocation of labor across industries, regions and jobs or occupations, ensuring that any disturbance to the labor market is not prolonged. The second view relates to the institutional factors that determine the structural level of unemployment, that is, unemployment related to sectoral shifts. Higher flexibility of the labor market is characterized by high employment and low structural unemployment rates. The view of flexibility considered in this study is flexibility defined by the variation on the speed of reallocation of labor across industries. Measures of the flexibility of the labor market are therefore broadly associated with important cross-country differences in the flow of workers across occupations. These differences can be explained by labor market regulations, but also by specific industrial responses to productivity and demand shocks. It is this flexibility that interacts with industry-specific volatility to influence demand for trade barriers. Essentially a country with very flexible labor market tends to have comparative advantage in industries exhibiting high intrinsic volatility.

\subsubsection{Political importance.}

2.5.3.1. Share of industry value added: To account for the believe that political influence of the industry is likely to be an important determinant of trade protection share of each industry value added is used as a proxy for industry size.

2.5.3.2. Share of industry labor: Labor share of the industry is another proxy used to capture the political influence of the industry. Grossman and Helpman (1994) show that price elasticity of demand for domestic products and price elasticity of supply of foreign 
products would affect the level of trade barriers because welfare losses and gains resulting from imposition of trade barriers depend on these elasticities. Since data on elasticities is not available, industry fixed effects are included to remedy for these industry specific factors. In addition, to account for country specific effects such as differences in the overall trade regime I include country specific effects.

2.5.4. Trade protection equation: I estimate the following baseline equation using industry-level data, 28 manufacturing industries, for many countries.

$$
\begin{array}{r}
T R_{c j}=\alpha_{0}+\alpha_{1} V O L_{c j}+\alpha_{2} V O L_{j} * F L E X_{c}+\alpha_{3} M P P_{c j}+ \\
\alpha_{4} E X P V A R_{c j}+\alpha_{5} V A D D_{c j}+\alpha_{6} L A B S_{c j}+\epsilon_{c j}
\end{array}
$$

where the subscripts $c$ and $j$, respectively, represent country and industry. The dependent variable, $T R$, denotes trade protection. Explanatory variables $V O L, M P P$ and EXPVAR represents, respectively, a measure of volatility, a measure of import penetration and a measure of export share in gross out. Import penetration is calculated by dividing gross imports by domestic consumption. The interaction variable of industry specific-volatility and flexibility of the labor market is represented by $V O L * F L E X$ . Note that I distinguish between measure of volatility that is specific to the industry and country, and one that is specific to industry. Other control variables, $L A B S$ and $V A D D$, denotes labor share of the industry and value added per worker, respectively. The value added per worker is a measure of labor productivity for the industry.

\subsection{Description of Data and Variables}

The sources of data include World Bank Development Indicators (WDI) database, a data set prepared by Nicita and Olarreaga (2006), Penn World Table database and Doing Business database. In particular, country-level measures of labor market flexibility are from World Bank development indicators (WDI) database and Doing Business database. Other country-level variables are from the Penn World Tables database. Nicita and 
Olarreaga constructed the industry-level data on production and trade protection. This data set is available on the World Bank database. I use data for 28 manufacturing industries and 68 countries. I average the data over the period 19952004 to take care of annual fluctuations.

As explained earlier high volatility generates demand for protection. The intuition is straightforward. Industries that exhibit high volatility tend to be prone to both domestic and external shocks. When agents experience increasing volatility they increase lobbying activity demanding protection from policymakers. It is expected volatility would be positively related to trade barriers after controlling for other determinants of trade barriers. In constructing measures of volatility, I distinguish between global industryspecific shocks and country-industry-specific shocks. Let $g_{c j t}$ be the deviations in growth of value added in country $c$ and industry $j$ at year t. The global industry-specific shock, $v_{j t}$, is measured as the cross-country average of $g_{c j t}$ in each of the industries as shown in the following equation.

$$
v_{j t}=\frac{1}{C} \sum_{c=1}^{c}\left(g_{c j t}\right)
$$

In the empirical estimation, $v_{j t}$ is averaged over the period and then used as a proxy for industry-specific volatility. To estimate a country-industry-specific volatility, first, country-specific disturbance are considered to be the within-country average of $g_{c j t}$ given by equation (37).

$$
\psi_{c t}=\frac{1}{J} \sum_{j=1}^{J}\left(g_{c j t}-v_{j t}\right)
$$

Then, the country-industry-specific volatility is specified as the difference between $g_{c j t}$ and the two shocks as shown in the following equations.

$$
v_{c j t}=g_{c j t}-v j t-\psi_{c t}
$$


The first explanatory variable on the baseline equation is constructed by averaging $v_{c j t}$ over the period 1995-2004. The second explanatory variable (interaction variable) is an interaction between (averaged over the period) and flexibility variable ( $F L E X)$. As pointed out earlier, interaction between industry-specific volatility and flexibility of the labor market is a source of comparative advantage and thus influence trade barriers. The idea is that industries that have comparative advantage would want tariffs eliminated to avoid possible retaliatory protection, by the trading partners, which would limit access to international markets.

Rigidity of employment index, reported by World Bank for most countries, is used to measure labor market flexibility. This index is an average of three indexes: cost of hiring index, cost of firing index, and rigidity of working-hours index. ${ }^{3}$ The index ranges from 0 to 100 , with higher values indicating more rigid regulations. This index is subtracted from 100 and then converted to logarithmic form to produce a measure of labor market flexibility variable.

Other industry-level exogenous variables are; import penetration $M P P$, share of export in gross output $E X P V A R$, value added per worker $V A D D$, and industry labor share $L A B S$. Import penetration captures demand for protection. It is estimated as industry-level gross imports divided by domestic consumption, where domestic consumption is calculated as industry-level domestic production plus net imports (net import equals imports minus exports).

Export share of gross output captures demand for protection. This variable is constructed as the industry-level of exports divided by industry output. Value added per worker $(V A D D)$ is a proxy for labor productivity and is calculated as value added of the industry, divided by the total number of employee in the industry. Industrys labor share $(L A B S)$ is a proxy capturing political importance of the industry. Labor share is calculated as the number of employee in the industry divided by total number of employees

\footnotetext{
${ }^{3}$ Botero et al (2004) uses other indexes (such as employment law index, collective relations laws index and social security laws index) to measure institutional differences across countries. However in this study, other indexes are used only for robustness checks.
} 
in the manufacturing industries. All variables are transformed into log form such that a percentage change on any explanatory variable leads to some percentage change of the response variable.

The estimated coefficient $\alpha_{1}$, in baseline equation is expected to be positive. This implies that a country prone to high volatility will demand higher protection all else equal. This is because agents associated with industries that are prone to volatility intensify their lobbying activity for protection form policymakers. Volatility also influences trade protection by interacting with labor flexibility. The interaction variable captures a source of comparative advantage of the industry. Estimated coefficient, $\alpha_{2}$, is therefore expected to be negative. This implies that increasing flexibility of the labor market reduces protection in comparative advantage industries. Countries with flexible labor market tend to have comparative advantage in industries that exhibit high intrinsic volatility. And, according to the theory of endogenous trade policy, comparative advantage industries rarely demand for protection because they are already competitive in the global market.

Increasing import penetration raises the demand for more protection and that means $\alpha_{3}$ is expected to be positive. On the other hand, retaliation, by other nations, targeting domestic export industries may lower the demand for protection. It is therefore important to control for industry share of exports. The effect of the change in the share of export, $\alpha_{4}$, is expected to be negative. Increasing the share of exports in the output of each industry lowers trade barriers. The political power of the industry is likely to be important. To control for the political power of the industry within the country, the industry share of labor within a country is used to capture industry size. Industries that are of significant size exert more political pressure. As a result, industry labor share is expected to have a positive relationship with trade protection. Likewise, the effect of the share of value added per work is expected to be positive. 


\subsection{Discussion of Estimated Results}

Table 1 shows estimation of the trade protection model with industry fixed effects. Estimated parameters on volatility and the interaction between volatility and flexibility have the expected signs and are statistically significant. These results hold for all four measures of trade protection including simple average tariffs, weighted tariffs, applied tariff for Most Favored Nation (MFN) as well as the weighted MFN tariffs. Table 7, column 2 and 3 indicates that a unit percentage change on industry volatility results to about 9 percent change in average tariffs and weighted tariffs, from the initial tariffs levels, holding other determinants of trade barriers constant. ${ }^{4}$ Column 4 and 5 denotes estimated values when tariffs are average MFN and weighted MFN respectively. For the two categories of tariffs the estimated values imply that a 1 percent change in industry volatility, courses 8 percent change in the level of tariffs. Estimates, on the interaction variable, are statistically significant and with the expected negative sign. The negative sign on the estimated parameters imply a push to lower tariffs in volatile industries when the labor market is flexible, or alternatively a push to increase tariffs in volatile industries as labor market become more rigid. This is consistent with the prediction of the theory of endogenous trade policy determination. If flexibility courses some form of comparative advantage for the more volatile industry then interested agents in these industries will lobby for lower barriers to mitigate retaliatory from their trading partners. It is therefore the case that when the labor market is made more flexible, say by eliminating excessive labor regulations and encouraging flow of jobs and workers, trade barriers are likely to fall in industries that exhibit high intrinsic volatility.

The share of imports to domestic consumption is positively related to tariff barriers. Estimated values, on import penetration, are statistically significant at 1 percent confidence interval. If imports share increases by 1 percent, it is likely to increases tariff barriers by 0.3 percent from the original level. Greater import penetration could raise

\footnotetext{
${ }^{4}$ The 9 percent change in average tariffs should not be mistaken to mean percentage point change in tariffs. Since tariffs are reported in percentages and they were transformed to log form, estimated values must be interpreted as a percentage changes from the initial tariffs levels.
} 
trade barriers because domestic private interest tends to demand more protection as import penetration increases. However, the magnitude of the estimated coefficient is very small. Table 8 presents estimated values for country fixed effects. The signs and magnitudes of estimated coefficients do not change significantly. However, estimates on trade protection equations with industry and country fixed effects presented in table 9 , indicates significant changes in the size of parameters.

\subsection{Concluding Remarks}

This empirical study add to the existing literature on the relationship between volatility and international trade. It exploits the theory of endogenous determination of trade policy to establish the link between volatility and trade protection. I find that volatility is an important source of demand for protection. As volatility of the industry increases, lobbying activity for protection intensifies and as a result industries exhibiting high volatility receive higher protection from politicians. In addition, labor market flexibility generate comparative advantage towards industries that are volatile. ${ }^{5}$ This effect reduces demand for protection. Consistent with the theory of endogenous trade policy, comparative advantage industries receive less protection. This implies that volatile industries may not lobby for protection if the labor market is sufficiently flexible to course comparative advantage in those industries. The interaction effect thus minimizes the demand for protection.

\footnotetext{
$\overline{5^{5} \text { This type of }}$ comparative advantage coursed by flexibility of the labor market is well articulated by Cunat and Melitz (2009)
} 


\section{Chapter 3}

\section{International Trade, Labor Market Flexibility, and Unemployment: EMPIRICAL EVIDENCE FROM LESS DEVELOPED COUNTRIES}

\subsection{InTRODUCTION}

Despite unemployment being one of the major economic issues in the public and political discourse on the effects of globalization, trade economists have generally tended to abstract away from unemployment. Studies examining relationship between trade and unemployment are more often confined on the periphery of mainstream trade literature. Only recently, trade economists have incorporated differences in labor market institutions and unemployment into the mainstream trade models.

In a nutshell, the new models, that incorporate labor rigidities and unemployment, suggest that increased exposure to international trade play an important role in the determination of unemployment. However, the effect of increased exposure to international trade on unemployment is either negative in some theoretical models or positive in others. For example, Helpman and Itskhoki (2010) find that unemployment rates in flexible countries (having less labor rigidities) depend on the pervasiveness of trade impediments and the level of labor market frictions. Helpman and Itskhoki conclude that disparity in labor market frictions and the interaction between trade barriers and labor market institutions create rich patterns of unemployment.

Several theoretical studies that introduce labor rigidities into the Ricardian and HeckscherOhlin comparative advantage models conclude that trade openness matters for the equilibrium rate of unemployment. However, in some cases openness is negatively related to unemployment while in other cases the relationship is positive. For example, Davidson et al. $(1988,1999)$ incorporate frictional unemployment in models of comparative advantage and find that the sign of the relationship between trade openness and unemployment depends on a comparison of capital-labor endowments across countries. Egger and Kreickemeier (2009) introduce fair wages into a model with increasing returns to 
scale and find that openness can increase unemployment. Felbermayr et al. (2011) introduce a standard Pissarides (2000) search model into a model with increasing return to scale and find that unemployment decrease with increased openness. To this end theoretical literature suggests there is no consensus on the long-run effects of increased international exchange on unemployment, which calls for empirical assessment to ascertain if trade openness lowers, raises or has no effect on unemployment. In addition, it is not well known how labor market institutions interact with trade policy to influences unemployment.

The main objective of this paper is to empirically examine the effects of trade policy and labor market flexibility on unemployment across developing countries (low income and lower middle income countries, based on the World Bank classifications). Focusing on developing countries is important because previous studies have mainly analyzed effects of trade policy and labor flexibility in relation to developed OECD countries. In addition, empirical studies that examine the effects of trade policy and labor flexibility are limited despite the fact that these issues are very common in the public and political debates. I examine the effects of trade policy and labor flexibility on unemployment for two categories of unemployed. The first category is the unemployment rate for those people with primary education (considered less skilled category), and the second category is the unemployment rate for those with secondary education (considered more skilled category), across developing countries.

\subsection{Exposure to international trade}

As the world continues to experience increased exposure to international trade a significant portion of the public feel that this trend generates forces that threaten job security. However, inside the economic profession exposure to international trade, for most part, is beneficial because it provides necessary environment for job creation. Existing literature has attempted to shed light on these differing views on the effects of trade 
openness on unemployment. According to Bernard et al. (2007) openness to trade increases job turnover as workers move from diminishing uncompetitive industries to the more productive expanding industries. Some studies support the view that frictional unemployment, at the aggregate level, increases due to adjustments of workers across industries. For example, Trefler (2004) documents that for NAFTA (North American Free Trade Agreement) worker reallocation temporarily raised unemployment.

Using the Ricardian comparative advantage model (based on relative technological differences) and Heckscher-Ohlin comparative advantage model (based on international differences in relative factor endowments), Dutt, Mitra and Ranjan (2009), henceforth DMR, find that trade openness is negatively related to unemployment in the Ricardian comparative advantage model, but has no significant effect in the Heckscher-Ohlin comparative advantage model. According to Felbermayr, Prat and Schmerer (2011) in the long run, openness to trade is negatively related to the structural rate of unemployment. Helpman and Itskhoki (2010) also find that trade openness can increase unemployment. There is more literature that is broadly related to trade openness and the dynamics in the labor market. For example, Egger and Kreickemeier (2008) examine how international fragmentation affects unemployment and wage inequality in an open economy model with efficiency wages. Koskela and Stenbacka (2010) find that outsourcing has a different effect on high-skill and low-skill workers, and that overall rate of unemployment decreases in outsourcing if the high skill worker force is relatively small.

On the relationship between differences in labor market institutions and unemployment it is commonly believed that continental Europe suffers from rigidities in the labor markets and this exacerbates unemployment problems and labor participation compared to North America that has relatively less rigid labor market. ${ }^{1}$ However, Nickell (1997) doubts the importance of the differences in labor market rigidity as determinants of unemployment. The author argues that some of the features of the labor markets that are

\footnotetext{
${ }^{1}$ Botero et al. (2004) emphasizes the view that high rigidity of the labor market is partly attributed to pervasive regulations of the labor market. The authors find heavier regulation of labor reduces labor force participation and causes high unemployment.
} 
referred rigidities in some European countries do not cause high unemployment. In a more recent work Nickell et al (2005) show that the evolution of labor market institutions partially explain unemployment rates.

The state of theoretical literature, on the effects of trade openness and labor flexibility on unemployment, points towards an empirical assessment. An empirical analysis that incorporates both trade policy and labor flexibility is necessary because, as suggested by Helpman and Itskhoki (2010), unemployment rate depends on interactions between trade impediments and labor market flexibility. In addition, both theoretical and empirical models that examine, separately, the effects of trade openness and labor flexibility have not arrived to a consensus on how these variables influence unemployment. Davidson and Matusz (2004) argue that whether trade openness affect the level of equilibrium unemployment depends on empirical evidence. Existing empirical studies on the effects of trade policy and labor flexibility mainly focus on developed countries, those that belong to the Organization for Economic Co-operation and Development (OECD). Yet trade impediments (measured by tariffs rates) are more pervasive among less developed countries than among OECD countries, but have received less attention. Moreover, unemployment rates are much higher across less developed countries compared to developed countries.

In view of these differing findings on the relationships between labor market institutions and unemployment, and the fact that empirical analysis on the impact of trade impediments and differences in the labor market institutions on unemployment are limited an empirical study that creates a deeper insight on these relationships is important.

\subsection{ThEORETICAL FRAMEWORK}

I estimate a baseline equation derived from the Dutt, Mitra and Ranjan (DMR) model of trade and unemployment. I present a summary of the DMR model to bring forth the underlying intuition upon which my empirical model is built. DMR model assumes a production structure in a two-sector economy, and trade that is based on a Ricardian 
comparative advantage. The model assumes an economy that produces a non-tradable final good, $\mathrm{Z}$, and two tradable intermediate goods, $X$ and $Y$. The production function for the final good is as follows:

$$
Z=\left[T X^{\beta-1} Y^{\beta}\right]\left[\beta^{\beta}(1-\beta)^{1-\beta}\right]^{-1}
$$

where, $0<\beta<1$. Let the prices of $\mathrm{X}$ and $\mathrm{Y}$ in terms of the final good be represented by $P_{x}$ and $P_{y}$ respectively. The unit cost for producing the final good is denoted as follows:

$$
c\left(P_{x}, P_{y}\right)=\frac{1}{T}\left(P_{x}\right)^{1-\beta}\left(P_{y}\right)^{\beta}
$$

This cost function can be equated to unit because the final good is chosen as the numeraire. Equation 39 above can be written as follows:

$$
\frac{1}{T}\left(P_{x}\right)^{1-\beta}\left(P_{y}\right)^{\beta}=1
$$

Relative demand for the two intermediate goods is denoted as follows.

$$
\frac{X^{d}}{Y^{d}}=\left[(1-\beta) P_{y}\right]\left[\beta P_{x}\right]^{-1}
$$

The labor market is similar to a standard Pissarides (2000) search model that is embedded in the two-sector economy. Idiosyncratic shock on the productivity of existing job-worker matches leads to job destruction. A firm rents capital to produce intermediate goods once a job-worker much is created. It is assumed that the firm can return the capital to the owner upon destruction of a job. Let the firms production functions in the two intermediate sectors be denoted as follows.

$$
\begin{aligned}
& x=a_{x} k_{x}^{n_{x}} \\
& y=a_{y} k_{y}^{n_{y}} \\
& 0 \leq n_{i} \leq 1
\end{aligned}
$$


where $k_{i}$ denotes the amount of capital used in sector $i=x, y, n_{i}$ is a parameter that captures capital intensity and $a_{i}$ is a sector technology parameter capturing total factor productivity. Let $L_{i}$ denote workers affiliated with sector $i$ and $u_{i}$ represents unemployment rate in sector $i$. It follows that the number of employed in the sector $i$ is given by $L_{i}\left(1-u_{i}\right)$.

Aggregate production functions in sectors $\mathrm{X}$ and $\mathrm{Y}$ are denoted the following equations.

$$
\begin{aligned}
& X=L_{x}\left(1-u_{x}\right) a_{x} k_{x}^{n_{x}} \\
& Y=L_{y}\left(1-u_{y}\right) a_{y} k_{y}^{n_{y}}
\end{aligned}
$$

The amount of capital in each sector is represented as follows. $K_{x}=k_{i} L-x\left(1-u_{x}\right)$; $K_{y}=k_{y} L_{y}\left(1-u_{y}\right)$. Given that the labor constraint is binding, such that $L=L_{x}+L_{y}$, then the market clearing condition in the capital market is captured by the following equation:

$$
K=L_{x} k_{x}\left(1-u_{x}\right)+L_{y} k_{y}\left(1-u_{y}\right)
$$

Equation 8, derived from equations 5 and 6, captures relative supply of the two intermediate goods.

$$
\frac{a_{x}\left(1-u_{x}\right) L_{x} k_{x}^{n_{x}}}{a_{y}\left(1-u_{y}\right) L_{y} k_{y}^{n_{y}}}=\frac{X^{s}}{Y^{s}}
$$

3.3.1. Labor Market: In the labor market the following matching function represents the flow of matches in each sector per unit time.

$$
M_{i}\left(v_{i} L_{i}, u_{i} L_{i}\right)=m_{i} v_{i}^{\alpha} u_{i}^{1-\alpha} L_{i}=m_{i} \phi_{i}^{\alpha} u_{i} L_{i}, 0<\alpha<1
$$

where $v_{i}$, denotes vacancy rate, $\phi=\frac{v_{i}}{u_{i}}$ captures market tightness, $m_{i}$ represents a scale parameter in the matching function and the parameter $\alpha$ denotes the vacancy intensity of the above Cobb-Douglas vacancy-worker matching function. The rates at which vacant jobs are filled and workers exit from unemployment are captured by expressions 47 and 
48.

$$
\begin{aligned}
\frac{M_{i}}{v_{i} L_{i}} & =m_{i} \phi_{i}^{\alpha-1} \\
\frac{M_{i}}{u_{i} L_{i}} & =m_{i} \phi_{i}^{\alpha}
\end{aligned}
$$

If the matches in sector $i$, are destroyed at a rate of $\theta_{i}$ per period, then the net flow into unemployment is given by the following equation:

$$
u_{i}=\theta\left(1-u_{i}\right)-m_{i} \theta_{i}^{\alpha} u_{i}
$$

The steady-state rate of unemployment, in sector $i$, is a constant denoted as follows:

$$
u_{i}=\frac{\theta_{i}}{\theta_{i}+m_{i} \phi_{i}^{\alpha}}
$$

The Bellman's equation below denotes the asset value of a vacant job, $V_{i}$.

$$
\rho V_{i}=-\lambda_{i}+m_{i} \phi_{i}^{\alpha-1}\left(J_{i}-V_{i}\right)
$$

The parameters, $\lambda_{i}$, denotes the cost of hiring in terms of final good, $\rho$ represents an exogenous discount factor, and $J_{i}$ is the value of a filled vacancy. Assuming free entry in job creation, that is, $V_{i}=0$, then the value of the filled vacancy is given as follows:

$$
J_{i}=\frac{\lambda_{i}}{m_{i} \phi_{i}^{\alpha-1}}
$$

where $i=X, Y$.

The asset value of an occupied vacancy satisfies the following Bellman's equation:

$$
\rho J_{i}=p_{i} a_{i} k_{i}^{n_{i}}-r k_{i}-w_{i}-\theta J_{i},
$$

where $r$ denotes rental cost of capital and $w_{i}$ is the wage in terms of numeraire good. The zero profit condition, expression 54, is derived from equations 52 and 53 .

$$
\frac{\left(\rho+\theta_{i}\right) \lambda_{i}}{m_{i} \phi_{i}^{\alpha-1}}=p_{i} a_{i} k_{i}^{n_{i}}-r k_{i}-w_{i}
$$


The maximization of the objective function, equation 53 , at given wage and rental rates gives the following optimal choice of $k_{i}$ :

$$
p_{i} a_{i} n_{i} k_{i}^{n_{i}-1}=r
$$

The wage is determined through a process of Nash bargaining between the worker and employer. The value of a job for an employer is given by $J_{i}$ and the surplus from the job is $W_{i}-U_{i}$, where $W_{i}$ is the discounted present value of employment in sector $i$. The term $U_{i}$ denotes the value of unemployment. The Bellman equations governing $W_{i}$ and $U_{i}$ are given by equation 56 and 57 below.

$$
\begin{gathered}
w_{i}+\theta\left(U_{i}-W_{i}\right)=\rho W_{i} \\
b+m_{i} \phi_{i}^{\alpha}\left(W_{i}-U_{i}\right)=\rho U_{i}
\end{gathered}
$$

The term $b$, represents a flow of some form of benefits (for example, unemployment insurance), in terms of final goods, transferred to the unemployed workers in each sector. The Nash bargaining gives the following expression:

$$
J_{i}\left(\frac{\sigma}{1-\sigma}\right)=W_{i}-U_{i}
$$

where $\sigma$, captures the bargaining power of workers. Equations 52, 56 and 57 leads to the following equation:

$$
\rho U_{i}=b+\left(\frac{\sigma}{1-\sigma}\right) m_{i} \phi_{i}^{\alpha} J_{i}=b+\left(\frac{\alpha}{1-\alpha} \lambda_{i} \phi_{i}\right.
$$

Equation 60 denotes the value of the wage and it is derived by substituting out $W_{i}$, $J_{i}$ and $\rho U_{i}$.

$$
w_{i}=\sigma\left(p_{i} a_{i} k_{i}^{n_{i}}-r k_{i}+\lambda_{i} \phi_{i}\right)+(1-\sigma) b
$$


Assuming no arbitrage condition, such that $U_{x}=U_{y}$, then the equilibrium condition is given as follows:

$$
\lambda_{x} \phi_{x}=\lambda_{y} \phi_{y}
$$

Assuming further that $m_{x}=m_{y}, \lambda_{x}=\lambda_{y}, \theta_{x}=\theta_{y}$ and $w_{x}=w_{y}$ implies search parameters are symmetric across sectors $X$ and $Y$. Since $\lambda_{x}=\lambda_{y}$, then from equation $24, \phi_{x}=\phi_{y}$. It also follows that equations 54 and 60 gives the wage expression:

$$
w_{i}=\left(\lambda_{i} \phi_{i}+\frac{\left(\rho+\theta_{i}\right) \lambda_{i}}{m_{i} \phi_{i}^{\alpha-1}}\right) \frac{\sigma}{1-\sigma}+b
$$

It can be shown, using the wage equation 62 , that for a given price ratio, increasing the value of $\lambda, \sigma$ or $b$ reduces $\phi$ causing unemployment to increase. I use an index for labor market rigidity to capture the effects of $\sigma$ and $b$ on the empirical model.

In this Ricardian comparative advantage formulation, factor intensities are also assumed to be identical in both sectors $X$ and $Y$, which implies the difference between the two production functions, for the two sectors, is a constant productivity term $a_{i}$. Given the assumptions of identical factor intensities and symmetric search parameters, equations 54 and 55 yield the following expression:

$$
p_{x} a_{x} k_{x}^{n}-n p_{x} a_{x} k_{x}^{n}=p_{y} a_{y} k_{y}^{n}-n p_{y} a_{y} k_{y}^{n}
$$

Equations 55 and 63 are used to derive the result that satisfy the following relative price equation:

$$
\frac{P_{x}}{P_{y}}=\frac{a_{y}}{a_{x}}
$$

Assuming that sector $X$ is the comparative advantage sector, before opening up to trade, the world price exceeds the price of sector $X$. Therefore the relative prices can be denoted as follows:

$$
\left(\frac{p_{x}}{p_{y}}\right)^{A}<\left(\frac{p_{x}}{p_{y}}\right)^{W}
$$


where superscript $A$ and $W$, respectively, denotes autarky and world. Moving from autarky to free trade the relative price of $X$ increases to equal the world relative price, such that $P_{x} a_{x}>p_{y} a_{y}$. This means, from equation 18 , the expression $a_{x} p_{x} k_{x}^{n}>a_{y} p_{y} k_{y}^{n}$ holds, also because $k_{x}>k_{y}$. Since rigidities in the labor market are identical for both sectors, Nash bargaining would equate wages for the two sectors. However, the compar-

ative disadvantage sector $Y$ shrinks because $a_{x} p_{x} k_{x}^{n}=w_{x}+\frac{(\rho+\theta) \lambda}{m \phi^{\sigma-1}}>a_{y} p_{y} k_{y}^{n}$. Therefore the country fully specializes in the comparative advantage sector $X$.

When the economy opens up for trade the unemployment falls because an increase in relative prices implies that $p_{x}$ increases and $p_{y}$ decreases. As a result, jobs are profitable in the comparative advantage sector at the existing autarky wage and for a given parameter $\phi$. On the other hand, in sector $Y$, the comparative disadvantage sector, jobs are not profitable given the lower $p_{y}$. To sum up the intuition of the trade-unemployment model; starting from autarky price, $p_{x}$ and $\phi$ increases causing the wage, $w$, to increase and unemployment, $u$, to fall. The theoretical model indicates that trade liberalization or reduction of trade barriers would cause unemployment rate to fall. The intuition in this model is the basis upon which the baseline equation, 29, is formulated. On empirical examination, using equation 29, for the sample of less developed countries, I find that the effect of trade liberalization on unemployment vary for skilled and unskilled labor force.

\subsection{Unemployment and the Flexibility of Labor Market.}

Since the paper focuses on both the effects of trade policy and labor market institutions on unemployment among skilled and unskilled labor force across a sample of less developed countries, it is vital to examine the definition and interpretation of labor market flexibility and the proxy that is used to capture this variable.

In a broader perspective, flexibility of the labor market relates to the mobility jobs and workers. Differences in mobility of workers, both geographically and between jobs are, for most part, attributed to labor laws and regulations that constitute differences 
of labor market institutions. Botero et al. (2004) constructed indices to capture these institutional differences for many countries by coding many laws and regulations that govern firm-worker employment contracts, dismissal procedures, hiring procedures and changes in hours worked. The index on rigidity of employment reported on the World Bank database (WDI database) is constructed following the formulation used by Botero et al. (2004). This rigidity of employment index is used in this paper to capture flexibility of the labor market. The index takes into account various regulatory practices governing firms in hiring and firing of workers in addition to other labor laws enshrined in a country legal system. The index is an average of four indices; an index capturing the cost of firing workers, an index capturing the cost of increasing hours worked, an index capturing alternative employment contracts and an index that measures other dismissal laws.

\subsection{Data Description And the Model.}

The estimated model assumes that trade occurs due to Ricardian comparative advantage described and unemployment results from search or 'congestion' externalities as in the standard Pissarides (2000) search model. If trade takes place only as a result of Ricardian type of comparative advantage then reducing trade barriers reduces unemployment. Opening up the economy for trade increases the value of the marginal product of labor in sector (this is the more productive sector and consequently the export sector) due to an increase in the domestic relative price of good produced in the sector. In this Ricardian set up trade leads to complete specialization, thus sector (the sector experiencing import competition), where the value of marginal product of labor would have been lower, shrinks under free trade such that the economy wide value of marginal product of labor increases. Workers and employers invest more in job search and job posting, and this leads to lower unemployment. I introduce labor market flexibility in the model consistent with the arguments by Helpman and Itskhoki (2010) that interactions of labor flexibility and trade policy are important in the determination of long term unemployment. 
Using country level data over the period 2000-2009 across 78 countries, I estimate a reduced equation with unemployment rate as the dependent variable and trade impediment, and labor market flexibility as the main explanatory variables. All variables are averaged over the period 2000-2009 in order to net out business cycle effects although controlling for output also minimizes the effects of business cycles.

I consider two categories of unemployment, unemployment rate as a percentage of labor force with primary education (considered less skilled category) and unemployment rate as a percentage of labor force with secondary education (considered as skilled category). Weighted tariffs are used to capture trade policy although real openness is also used for robustness. To capture labor market flexibility, I use measures of rigidity of employment indices constructed by Botero et al. (2004).

I estimate the following model for a sample of 57 less developed countries.

$$
U N=\alpha_{0}+\alpha_{1} T A R I F F+\alpha_{2} F L E X V A R+\alpha_{3} O U T P U T V O L+\alpha_{4} P O P 1564+\epsilon
$$

Average tariff rates are used to capture trade impediments but other measures of trade impediments are used to check for robustness. ${ }^{2}$ Rigidity of employment index is used to proxy for labor market flexibility. Rigidity of employment index is an average of three indices, cost of hiring index, cost of firing and rigidity of work hours developed by Botero et al. (2004). This index captures important cross-country differences in the flow of workers and jobs across occupations.

3.5.1. Control variables. To control for the effects of short run fluctuations, a measure of output volatility is used. Following Ramey and Ramey (1995), countries with high volatility have lower growth and high unemployment. Output volatility is measured as the standard deviation of annual GDP per capita growth (measured as year-differenced $\log$ GDP per capita) for each country in the sample over the period 2000-2009. The

\footnotetext{
${ }^{2}$ There are many protectionist policy instruments used by countries (for example, antidumping duties, quotas, non-automatic licensing, tariffs, etc.) such that it is not easy to find a single measure that captures all trade policy instruments. As a result of this limitation, real openness, Ropen $=2 \frac{\operatorname{Imports} s_{c}}{p p p G D P_{c}}$, is used as a measure of trade impediments for robustness checks.
} 
effects of the size of the economy could be important in the determination of long-term unemployment. Real GDP and the working-age population (ages 15 to 64 years) are used to control for the effects of economy size. These two controls for the size of the economy also controls for the level of development. A variable indicating existence of minimum wage is included as a labor market covariate. To control for the trade-offs between inflation and unemployment, I include nominal interest rate and inflation rate as additional controls. These two controls are added based on the understanding that monetary policy is frequently used as a tool to manage the trade-offs between inflation and unemployment. Inclusion of these control variables in the estimated equation does not alter either the signs or the magnitudes of estimated coefficients on tariff or labor flexibility.

\subsubsection{Endogeneity of trade policy and instrumental variable estimation.}

Policymakers in countries experiencing high unemployment could experience pressure from lobbies and industries most affected to impose trade barriers if affected industries believe imports course unemployment. There is potential reserve causality where by increasing unemployment could influence trade policy. This problem can be mitigated by use of a valid instrument for trade policy. Two instrumental variables that can be used include average bilateral distance of a countrys trading partners and the number of years a country stays outside WTO (World Trade Organization) or its predecessor GATT (General Agreement on Tariffs and Trade) since its inception in 1948. The remoteness of a countrys trading partners could generate an incentive to set low tariffs in order to lower cost of import. Ross (2004) finds that nearly all countries lowered their tariffs barriers significantly after acceding to GATT. After accession to GATT countries took about 10 years on average to open up their economies. So the degree of protectionism is positively related to the duration a country stays outside GATT. 


\subsection{Estimated RESULtS}

Table 11 shows results from OLS estimation with only the trade policy covariates. The coefficient estimate on average tariff rate is positive in the first equation (UN1) unemployment rate as a percentage of labor force with primary education. This positive relationship is consistent to the predictions in the theory that increase in trade barriers could increase unemployment. However, it is not possible at this point to make inference on the magnitude of this estimate with other control variables excluded. The variable capturing trade policy (measure of real openness) has a negative relationship with the first category of unemployment (UN1), as expected. For the second category of unemployment rate UN2, (unemployment as a percentage of labor force with secondary education) the coefficient estimates on tariff and real openness are negative and positive respectively. This implies that an increase in tariff barriers lowers UN2 category of unemployment. Table 12 presents negative relationships between labor flexibility unemployment. This signals that making labor market more flexible (say by lowering the cost of hiring and firing, increasing flexibility of work hours) could lower both categories of unemployment.

Table 13 shows both OLS and IV estimates with all control variables included. The signs on the estimates for both trade policy and labor flexibility do not change. However, the magnitudes change significantly. Column 2 (OLS estimates) indicates that a 1percent increase in tariffs decreases the first category of unemployment (UN1) by 0.35 percent and the estimate is significant at 1percent confidence interval. The effect of flexibility is negative and statistically significant at 5 percent confidence interval. The IV estimates for tariffs and flexibility presented on column 3 have the expected sign and are significant at 10 percent and 5 percent confidence intervals respectively. The magnitudes for the IV estimates are higher than the OLS but are weakly significant. The p-value reported from Hansen-Sargan tests could not reject the null hypothesis of over-identifying restrictions, which confirms the instruments used are valid. Columns 4 and 5, present OLS and IV estimates for the second category of unemployment (UN2). Tariffs and flexibility 
partially explain unemployment (UN2). However, the sign on the coefficient estimate on tariffs is inverted. It means that an increase in tariffs decreases this category of unemployment.

\subsection{Concluding Remarks}

Trade barriers and rigidities in the labor market exacerbate unemployment in developing countries. However, increases in tariffs have difference effects among the unskilled and skilled workers. Increasing tariffs increases unemployment among relatively unskilled workers while it lowers unemployment among relatively skilled workers. The effects of tariffs on unemployment are robust even after controlling for the size of the economy and the effects of business cycles. Instrumental variable estimates (IV) reveal that endogeneity of trade policy and unemployment leads to underestimation of the effects of trade policy on long-term unemployment. These findings suggest trade policy influences unemployment in the sample of less developed countries, and this is consistent with the Ricardian predictions. However, this is true only for unemployment among the relatively unskilled workers. Ricardian predictions are inverted for unemployment among relatively skilled workers. The varying effects of trade policy on different skill category could be reconciled by the infant-industry protection argument pioneered by John Stuart Mill in the 19th century. The infant industry argument asserts that protecting infant industries during the learning process until they mature and become competitive could increase welfare. Given this argument, if the relatively skilled workers are primarily associated with infant industries (industries that are maturing by learning new external technologies) then increasing tariffs protects these industries from external competition. When these industries mature, productivity improves thus hiring more skilled workers and lowering unemployment among this category of workers. More recently, Melitz (2005) develop a theoretical model on infant industry protection. He shows that tariffs could actually increase welfare when industries are protected during the process of learning new external technologies. 


\section{REFERENCES}

[1] Balassa, Bela. 1965. Trade liberalization and revealed comparative advantage. Manchester School of Economics and Social Studies 33: 92-123.

[2] Baldwin, Robert. 1985. The Political Economy of US Import Policy. Cambridge: MIT Press.

[3] Bekaert, Geert, Campbell Harvey, and Christian Lundblad. 2006. Growth volatility and financial liberalization. Journal of International Money and Finance 25: 370-403

[4] Bernard, Andrew, Stephen Redding and Peter Schott. 2007. Comparative advantage and heterogeneous firms. Review of Economic Studies 74, 31-66.

[5] Bernheim, Douglas and Michael Whinston. 1986. Menu auctions, resource allocation, and economic influence. Quarterly Journal of Economics 101: 1-31.

[6] Black, Duncan. 1958. The Theory of Committees and Election. Cambridge: University Press.

[7] Botero, Juan, Simeon Djankov, Rafael La Porta, and Andrei Shleifer. 2004. The regulation of labor. Quarterly Journal of Economics 119, 1339-82.

[8] Bown, Chad. 2011. The Great Recession and Import Protection: The Role of Temporary Trade Barriers. The International Bank for Reconstruction and Development/The World Bank: Washington DC.

[9] Brock, William and Stephen Magee. 1978. The economics of special interest politics: the case of the tariff. American Economic Review 68: 246-50.

[10] Chor, Davin. 2010. Unpacking sources of comparative advantage: A quantitative approach. Journal of International Economics 82: 152-167.

[11] Costinot, Arnaud. 2009. On the origins of comparative advantage. Journal of International Economics 77: 255-264.

[12] Cunat, Alejandro and Marc Melitz. Forthcoming. Volatility, labor market flexibility, and the pattern of comparative advantage. Journal of European Economic Association.

[13] Davidson, Carl, Lawrence Martin, and Steven Matusz. 1998. The structure of simple general equilibrium models with frictional unemployment. Journal of Political Economy 96 (6), 1267-1293.

[14] 1999. Trade and search-generated unemployment. Journal of International Economics 48 (2), 271-299.

[15] Davidson, Carl, and Steven Matusz. 2004. International Trade and Labor Markets: Theory, Evidence, and Policy Implications, W. E. Upjohn Institute, Kalamazoo, MI.

[16] Di Giovanni, Julian and Andrei Levchenko. 2009. Trade openness and volatility. Review of Economic Statistics 91: 558-85.

[17] 2011. The risk content of exports: a portfolio view of international trade. NBER International Seminar on Macroeconomics.

[18] Di Tella, Rafael and Robert MacCulloch. 2005. The consequences of labor market flexibility: panel evidence based on survey data. European Economic Review 49: 1225-59.

[19] Dornbusch, R., S. Fischer, and P.A. Samuelson.1977. Comparative advantage, trade and payments in a Ricardian model with a Continuum of goods. American Economic Review 67: 823-839.

[20] Dutt, Pushan and Devashish Mitra. 2002. Endogenous trade policy through majority voting: an empirical investigation. Journal of International Economics 58: 107-133.

[21] Dutt, Pashan, Devashish Mitra, and Priya Ranjan. 2009. International trade and unemployment: Theory and cross-national evidence. Journal of International Economics 78 (1), 32-34.

[22] Easterly, William, Roumeen Islam, and Joseph E. Stiglitz. 2001. Shaken and stirred: explaining growth volatility, in B. Pleskovic and N. Stern (Eds), Annual World Bank Conference on Development Economics.

[23] Egger, Harmut and Udo Kreickemeier. 2008. International fragmentation: boon or bane for domestic employment? European Economic Review 52 (1), 116-132.

[24] 2009. Firm heterogeneity and the labor market effects of trade liberalization. International Economic Review 52 (2), 355-362.

[25] Feenstra, Robert. 2003. Advanced International Trade: Theory and Evidence. New Jersey: Princeton University Press.

[26] Feenstra, Robert and Tracy Lewis. 1991. Negotiated trade restrictions with private political pressure. Quarterly Journal of Economics106: 1287-1307. 
[27] Felbermayr, Gabriel, Julie Prat, and Hans-Jórg Schmerer. 2011. Trade and unemployment: What do the data say?European Economic Review: doi:10.1016/j.eurocrev.2011.02.003.

[28] -. 2011. Globalization and labor market outcomes: wage bargaining, search frictions, and firm heterogeneity. Journal of Economic Theory 146 (1), 39-73.

[29] Findlay, Ronald and Stanislaw Wellisz. 1982. Endogenous tariffs, the political economy of trade restrictions, and welfare, in import competition and response, edited by Jagdish N. Bhagwati. Unv. Chicago Press.

[30] Gawande, Kishore, and Pravin Krishna. 2003. The Political Economy of Trade Policy: Empirical Approaches in Eun Kwan Choi and James Harrigan (Eds), Handbook of International Trade New York: Basil Blackwell.

[31] Grossman, Gene M. and Elhanan Helpman. 1991. Innovation and Growth in the Global Economy. Cambridge: MIT Press.

[32] 1994. Protection for sale. American Economic Review: 833-50.

[33] Helpman, Elhanan and Oleg Itskhoki. 2010. Labor market rigidities, trade and unemployment. The Review of Economic Studies 77: 1100-37.

[34] Hillman, Arye. 1982. Declining industries and political support protectionist Motives. American Economic Review 72: 1180-7.

[35] -.1989. The political economy of protection. New York: Harwood Academic Publishers.

[36] Imbs, Jean. 2007. Growth and volatility. Journal of Monetary Economics 54: 1848-1862.

[37] Koren, Miklos and Silvana Tenreyro. 2007. Volatility and development.Quarterly Journal of Economics 122: 243-287.

[38] Kose, Ayhan, Eswar Prasad, and Macro Terrones. 2003. Financial integration and macroeconomic volatility. IMF Staff Papers Special Issue 50: 119-41.

[39] Koskela, Erkki and Rune Stenbacka. 2010. Equilibrium unemployment with outsourcing and wage solidarity under labor market imperfections. European Economic Review 54, 376-392.

[40] Krugman, Paul. New York Times. 2009. Protectionism and stimulus. February 1. http://krugman.blogs.nytimes.com/2009/02/01/protectionism-and-stimulus

[41] -.1987. The narrow moving band, the Dutch disease, and the competitive consequences of Mrs. Thatcher. Journal of Development of Economics 27, 41-55.

[42] Lauren, Thomas and Sandeep Mahajan. 2005. Volatility Income Distribution, and Poverty in Joshua Aizenman and Brian Pinto (Eds), Managing Volatility and Crises: A practitioners Guide, 101-136, (New York: Cambridge University Press).

[43] Lee, Jong-Wha and Phillip Swagel. 1997. Trade barriers and trade flows across Countries and industries. Review of Economics and Statistics 79: 372-82.

[44] Levchenko, Andrei A. 2007. Institutional quality and international trade. Review of Economic Studies 74: 791-819.

[45] Magee, Stephen, William Brock, and Leslie Young. 1989. Black hole tariffs and endogenous policy theory: political economy in general equilibrium. New York: Cambridge Univ. Press.

[46] Melitz, Marc. 2005. When and how should infant industries be protected? Journal of International Economics 66: 177-196.

[47] Mill, John Stuart. 1848. Principles of political economy. In Robson, J.M. (Ed.), collected works of John Stuart Mill, Vol. III. University of Toronto Press: 918-919.

[48] Nicita, Alessandro and Marcelo Olarreaga. 2006. Trade production and protection 19762004. Development Economics Research Group, World Bank, Washington, D.C.

[49] Nickell, Stephen. 1997. Unemployment and labor market rigidities: European versus North America. Journal of Economic Perspectives 11 (3), 55-74.

[50] North Douglas. 1991. Institutions. Journal of Economic Perspectives 5: 97-112.

[51] Nunn, Nathan. 2007. Relationship-specificity, incomplete contracts, and the pattern of trade. Quarterly Journal of Economics, 122: 569-600.

[52] Nunn, Nathan and Daniel Trefler. 2010. The structure of tariffs and long-term growth. American Economic Journal: Macroeconomics: 158-94.

[53] Pissarides, Christopher. 2000. Equilibrium Unemployment Theory, 2nd edition, MIT Press, Cambridge, MA. 
[54] Ramey, Garey and Valerie Ramey. 1995. Cross-country evidence on the link between volatility and growth. American Economic Review 85: 1138-1151.

[55] Rodrik, Dani. 1997. Has Globalization Gone too Far? Institute for International Economics. Washington, DC.

[56] Rose, Andrew. 2004. Do we really know that the WTO increases trade? America Economic Review 94: $98-114$

[57] Shapiro, Carl and Joseph Stiglitz. 1984. Equilibrium unemployment as a worker discipline device. American Economic Review, 74: 433-44.

[58] Trefler, Daniel. 1993. Trade liberalization and the theory of endogenous protection: an econometric study of U.S. import policy. Journal of Political Economy 101: 138-60.

[59] - 2004. The long and short of Canada-US free trade agreement. American Economic Review 94 (4), 870-895.

[60] Wacziarg, Romain and Jessica S. Wallack. 2004. Trade liberalization and intersectoral labor movements. Journal of International Economics 64: 411-39.

[61] Wooldridge, Jeffrey. 2002. Econometric Analysis of Cross Section and Panel Data. MIT Press, Cambridge, Massachusetts. 


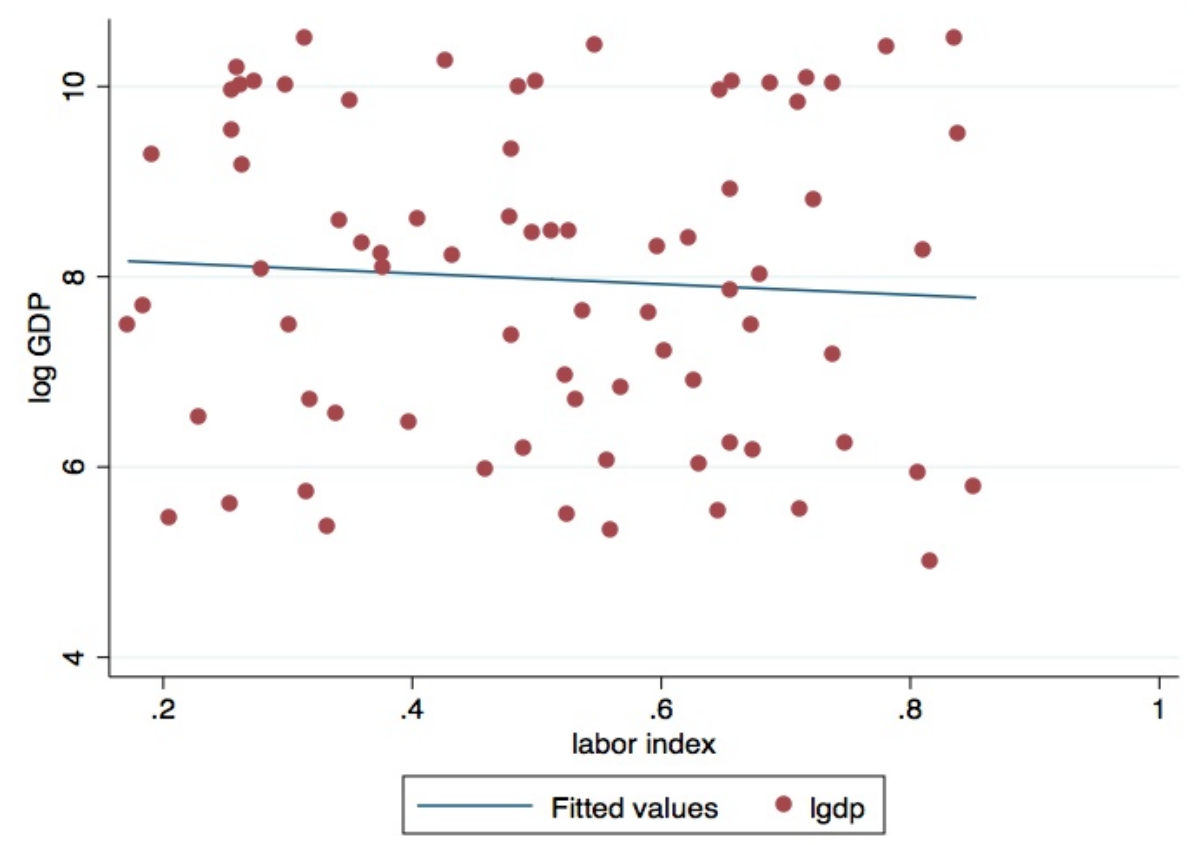

Figure 1. Correlation between log GDP and labor flexibility index for many countries, both developed and less developed. 


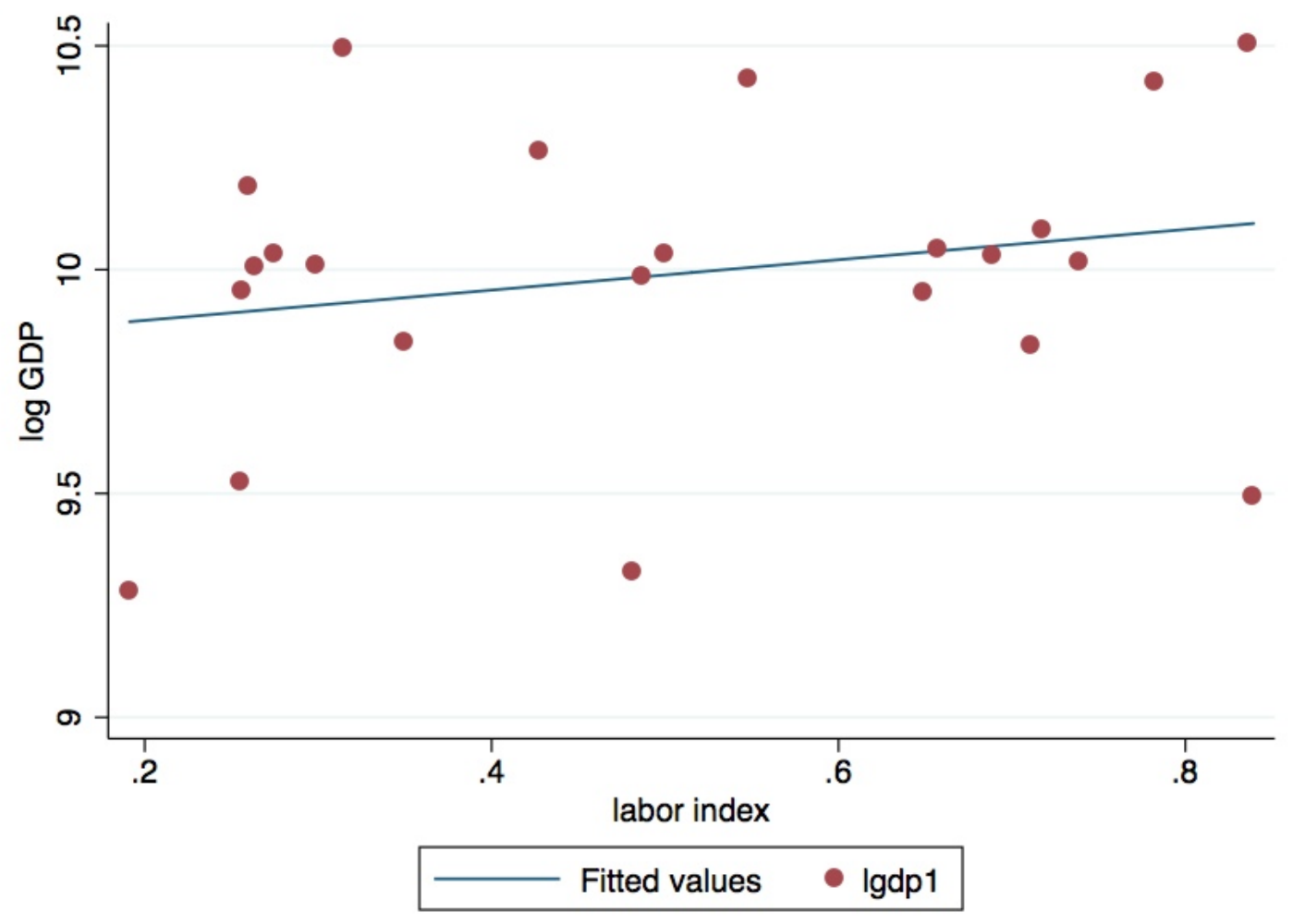

FiguRE 2. Correlation between log GDP and labor flexibility index for developed countries. 


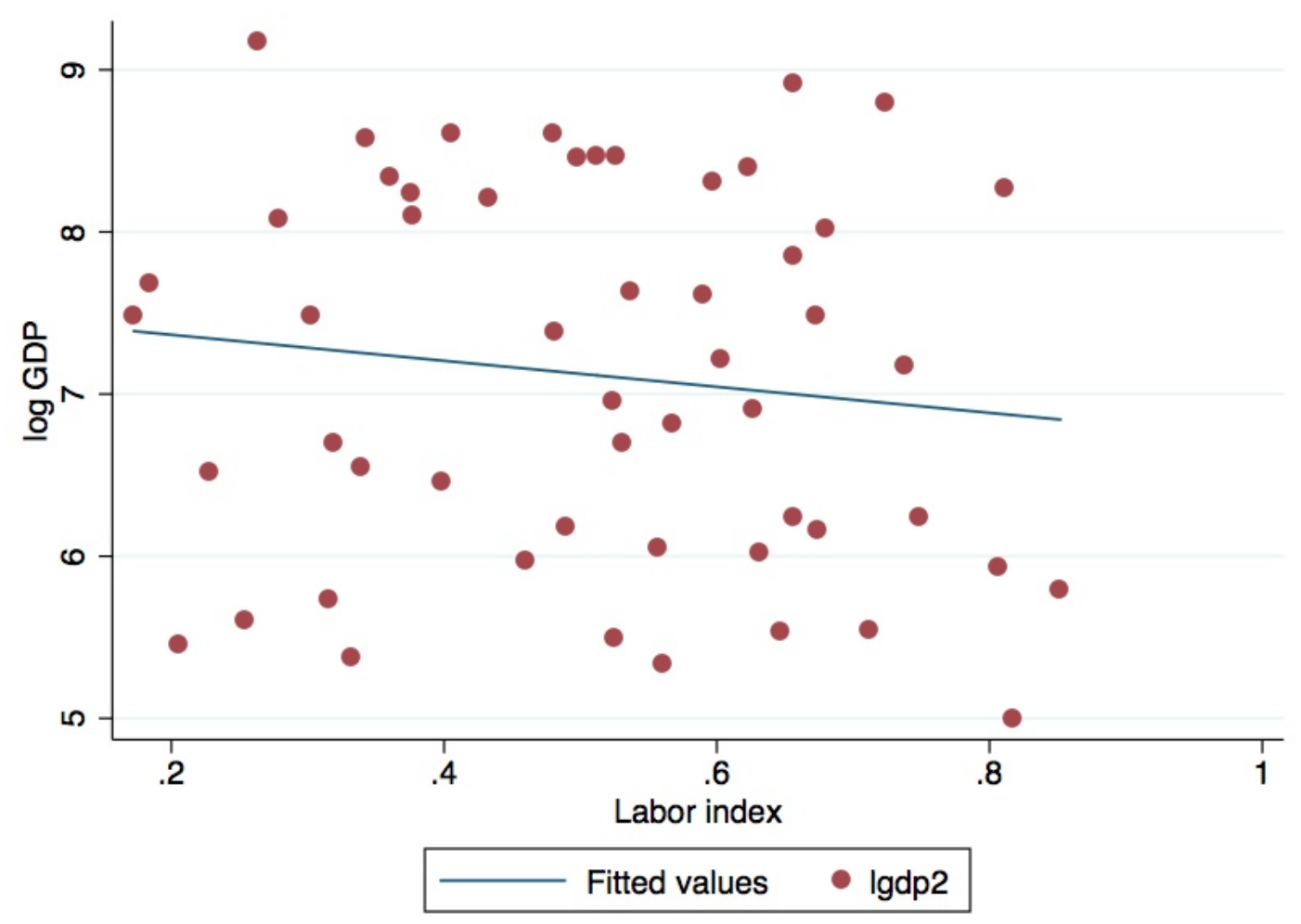

Figure 3. Correlation between log GDP and labor flexibility index for less developed countries. 

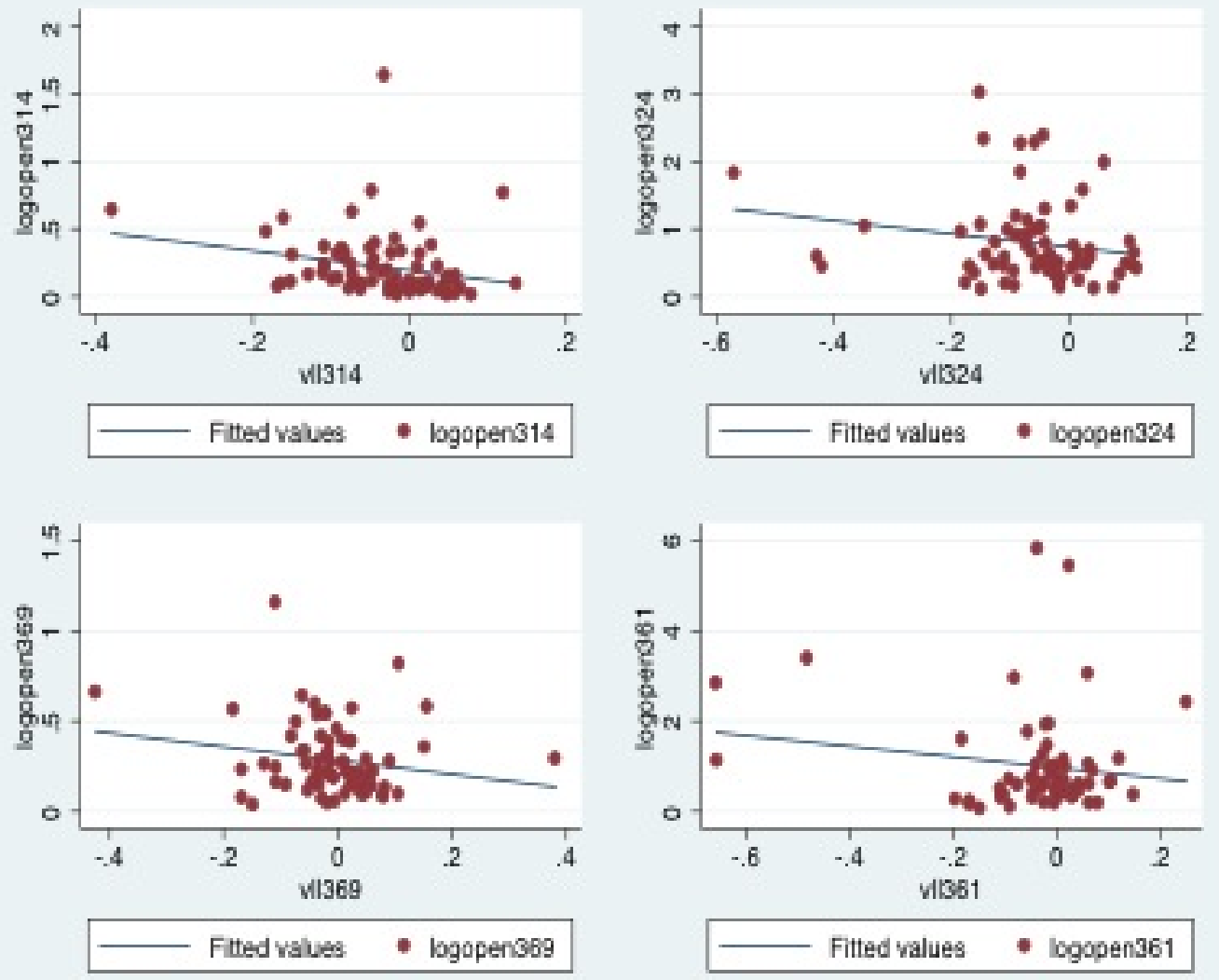

FiguRE 4. Correlation between trade (exports plus imports divided by output) and volatility. 

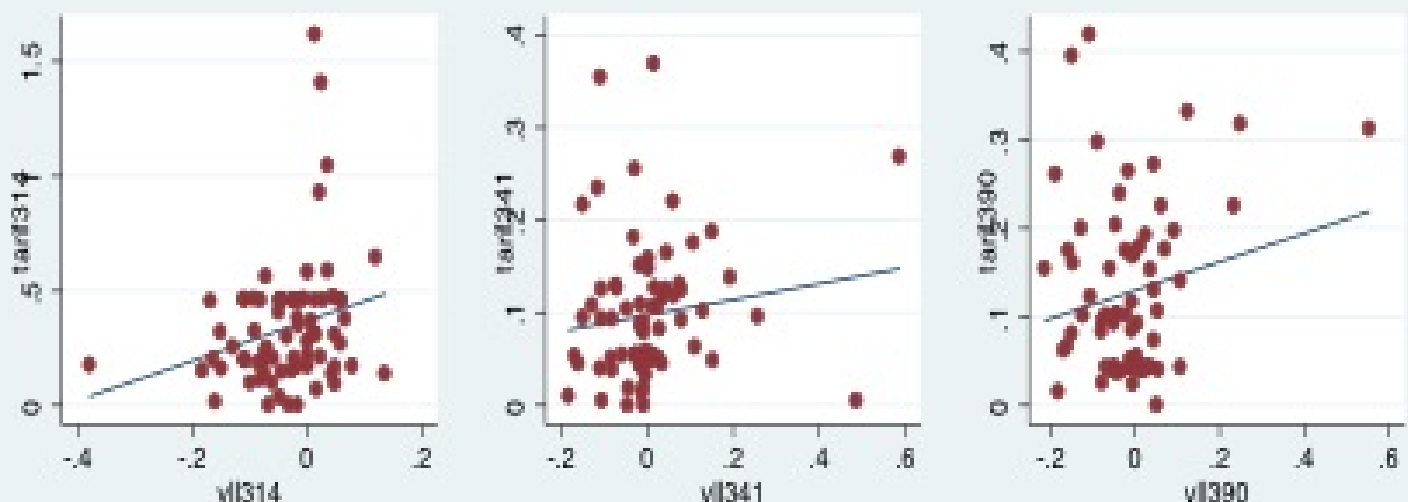

Fitted values • tarif314

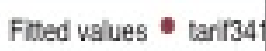

Fined values - terisgo
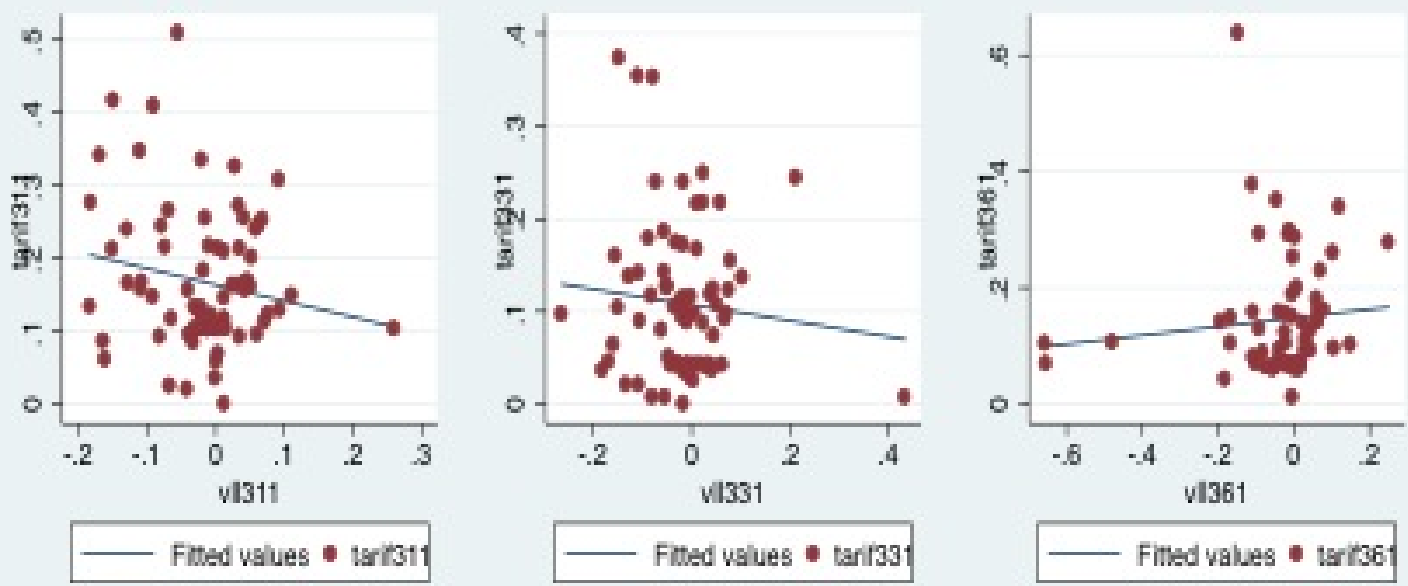

FiguRE 5. Relationships between tariffs and volatility of value added. 


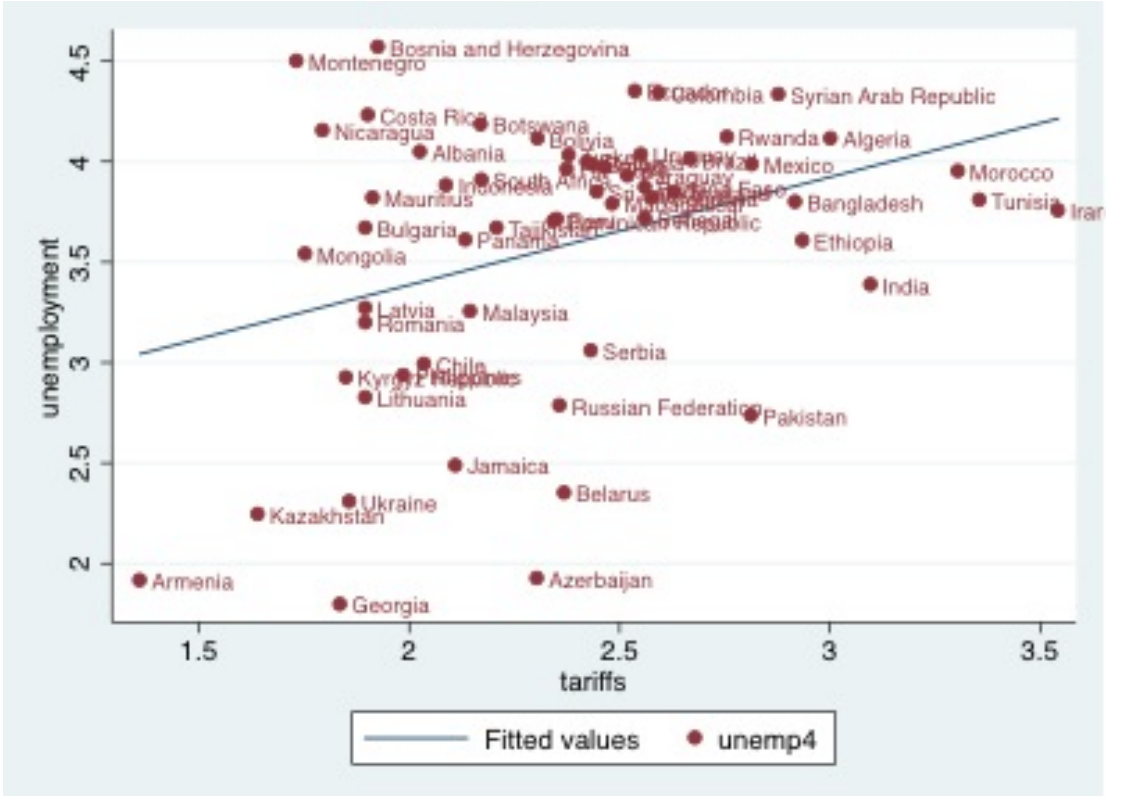

Figure 6. Correlation between unemployment rate and tariff rate (simple MFN tariff rate. 


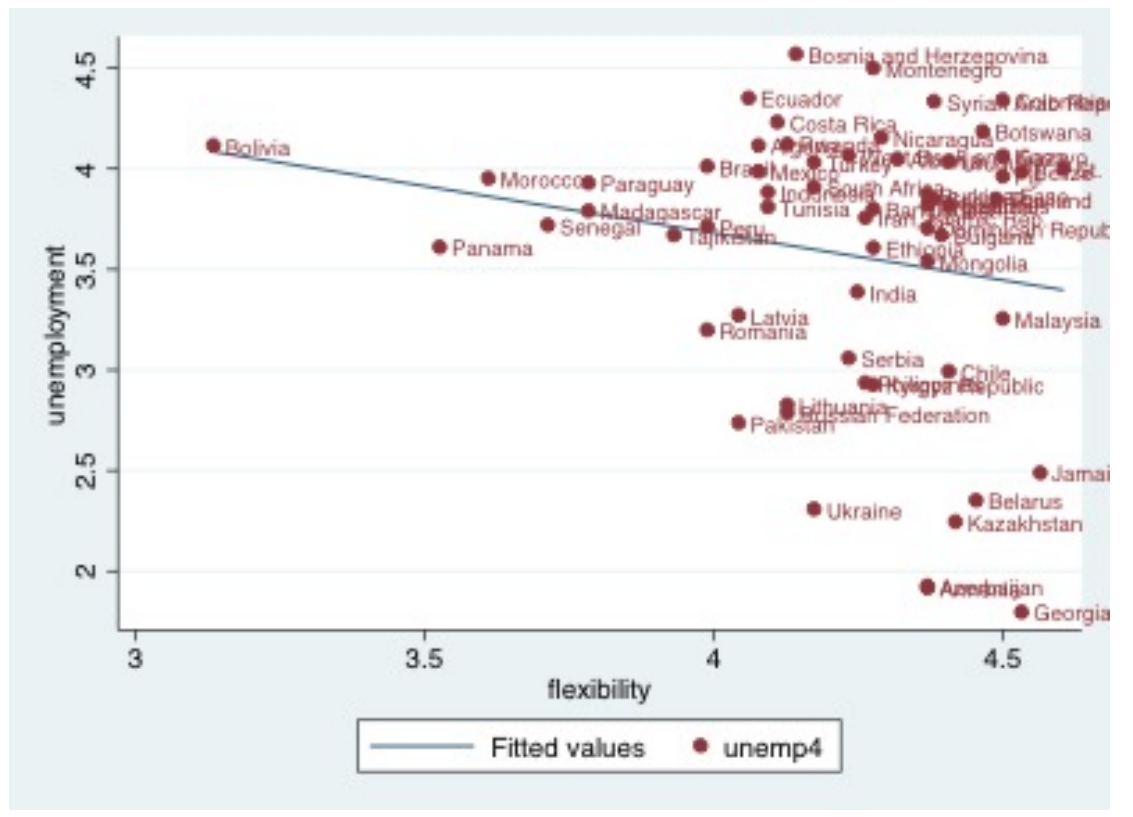

FiguRE 7. Correlation between unemployment and labor flexibility. 
TABLE 1. Values of labor index constructed by Botero et al. (2004) and GDP per capita, PPP (constant 2000 US dollars), averages for the period 1994-2004.

\begin{tabular}{lcc}
\hline \hline Country & GDP per capita & Labor Flexibility Index \\
\hline Japan & 36467.1 & 0.163937 \\
Norway & 36104.5 & 0.685338 \\
Switzerland & 33701.4 & 0.452044 \\
United States & 33431 & 0.217594 \\
Denmark & 28744.4 & 0.572687 \\
Sweden & 26507.4 & 0.740487 \\
United Kingdom & 24033.8 & 0.282408 \\
Ireland & 23049.4 & 0.342714 \\
Netherlands & 22830.9 & 0.725569 \\
Austria & 22829.8 & 0.500656 \\
Singapore & 22690.8 & 0.311639 \\
Canada & 22380.1 & 0.261536 \\
Germany & 22238.7 & 0.701526 \\
Finland & 22151.5 & 0.736604 \\
Belgium & 21733.9 & 0.513275 \\
France & 20988.7 & 0.744279 \\
Australia & 20904.3 & 0.3515 \\
Italy & 18754.8 & 0.649927 \\
Israel & 18568.2 & 0.289014 \\
Spain & 13707 & 0.744681 \\
New Zealand & 13249.9 & 0.160721 \\
Greece & 11209 & 0.518858 \\
Portugal & 10744.7 & 0.808767 \\
Slovenia & 9604.43 & 0.735911 \\
\hline \hline
\end{tabular}




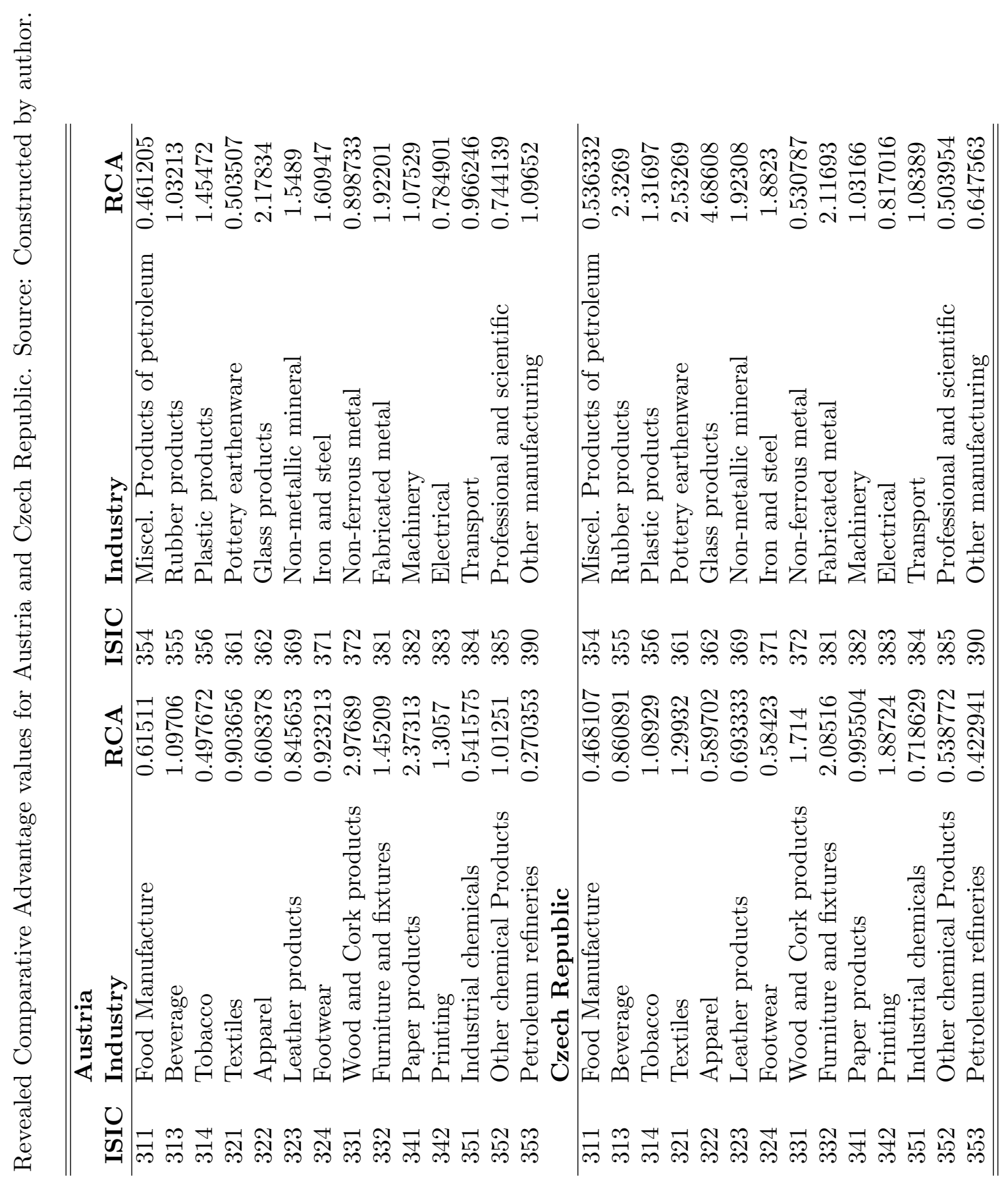

桴 


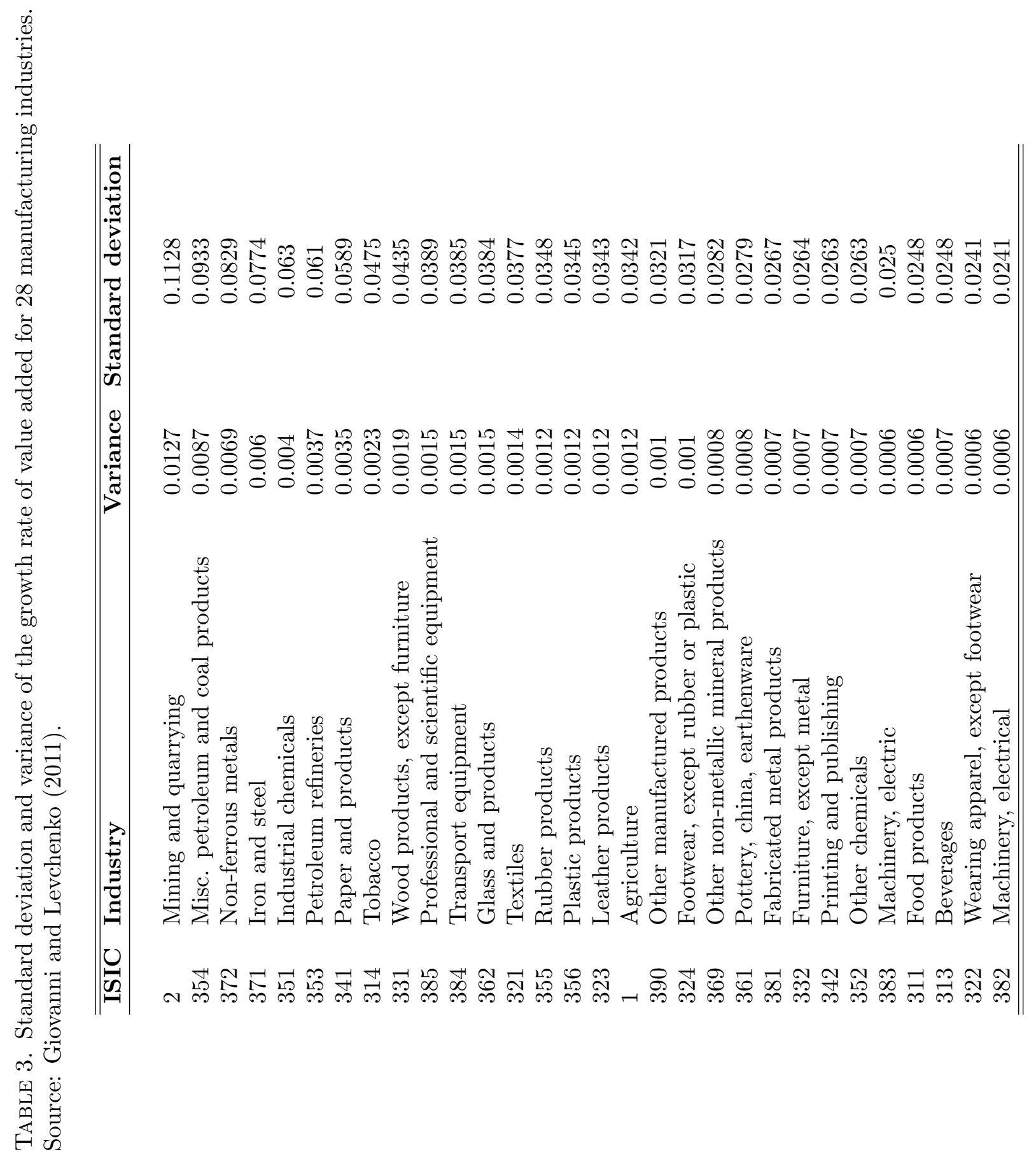




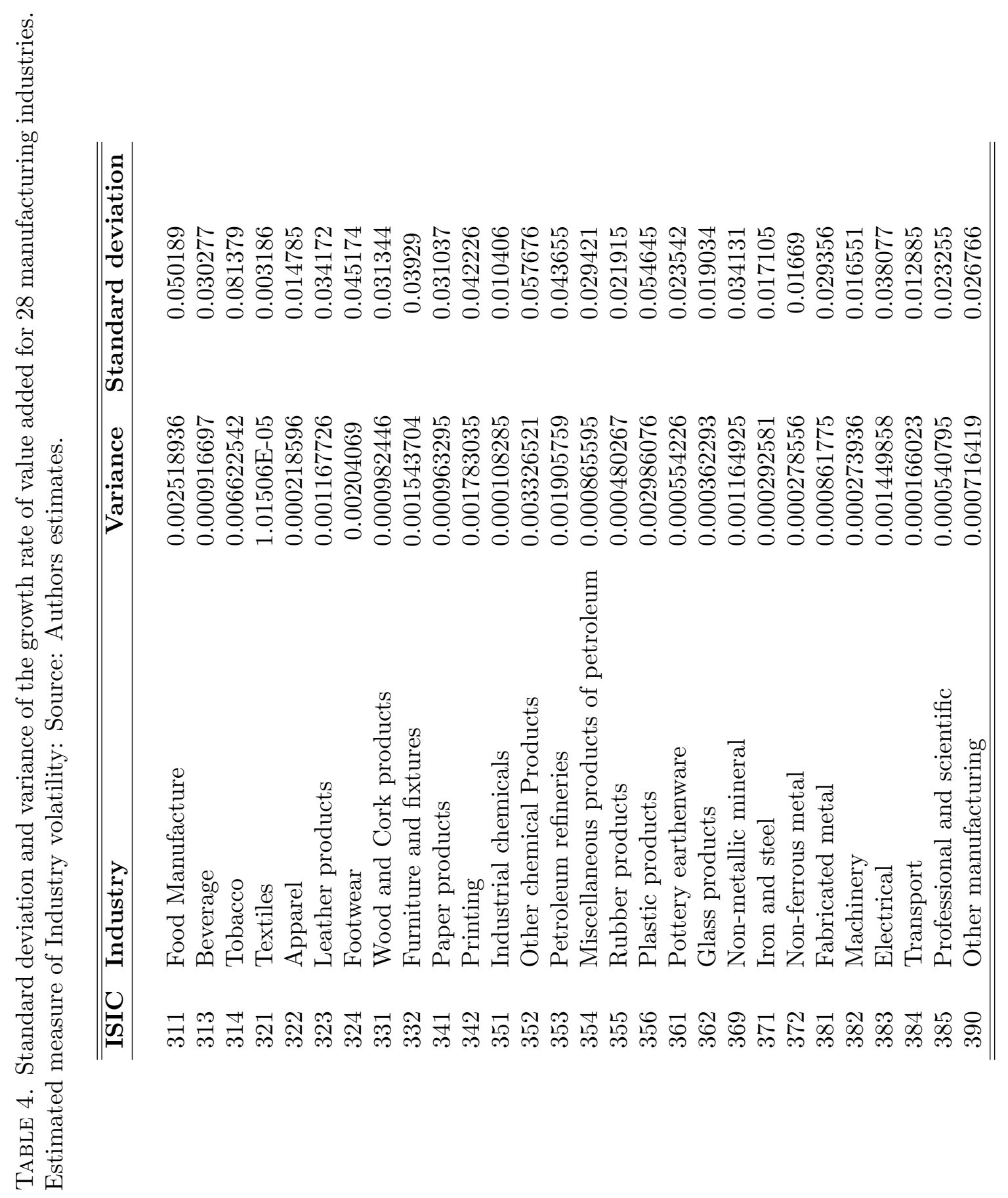


TABLE 5. Estimated results with industry and country fixed effects

\begin{tabular}{lccc}
\hline \hline & $(1)$ & $(2)$ & $(3)$ \\
\hline VARIABLES & & & \\
$V O L_{j} * F L E X_{c}$ & $0.621^{* * *}$ & $0.236^{* * *}$ & $0.389^{* * *}$ \\
& $(0.190)$ & $(0.0732)$ & $(0.141)$ \\
$K_{c j} * F L E X_{c}$ & $-0.0652^{* * *}$ & -0.0479 & $1.062^{* * *}$ \\
& $(0.0177)$ & $(0.150)$ & $(0.278)$ \\
$K_{c j} * K_{c}$ & $0.0191^{* * *}$ & $0.251^{*}$ & $1.042^{* * *}$ \\
& $(0.00295)$ & $(0.147)$ & $(0.287)$ \\
& & & 1,495 \\
Observations & 1,495 & 1,495 & 0.341 \\
R-squared & 0.37 & 0.21 & \\
& & & Yes \\
\hline$\mu_{j}$ & Yes & No & Yes \\
$\varphi_{c}$ & No & Yes & \\
\hline \hline \multicolumn{2}{c}{ Robust standard errors in parentheses, ${ }^{* * *} p<0.01, * * p<0.05, * p<0.1$}
\end{tabular}


TABLe 6. A Probit estimation

\begin{tabular}{|c|c|c|c|c|}
\hline & & $(1)$ & $(2)$ & $(3)$ \\
\hline \multirow[t]{7}{*}{ EQUATION } & VARIABLES & & & \\
\hline & $V O L_{j} * F L E X_{c}$ & $\begin{array}{c}0.762^{* * *} \\
(0.167)\end{array}$ & $\begin{array}{c}0.186^{* * *} \\
(0.0667)\end{array}$ & $\begin{array}{c}0.154^{* * *} \\
(0.0546)\end{array}$ \\
\hline & $K_{c j} * F L E X_{c}$ & $\begin{array}{c}-0.0756^{* * *} \\
(0.0160)\end{array}$ & $\begin{array}{c}-0.0954 \\
(0.137)\end{array}$ & $\begin{array}{c}-0.0716^{* * * *} \\
(0.0160)\end{array}$ \\
\hline & $K_{c j} * K_{c}$ & $\begin{array}{c}0.0156^{* * *} \\
(0.00274)\end{array}$ & $\begin{array}{c}0.215 \\
(0.135)\end{array}$ & $\begin{array}{c}0.0147^{* * *} \\
(0.00274)\end{array}$ \\
\hline & Observations & 1,514 & 1,514 & 1,514 \\
\hline & $\mu_{j}$ & Yes & No & Yes \\
\hline & $\varphi_{c}$ & No & Yes & Yes \\
\hline
\end{tabular}




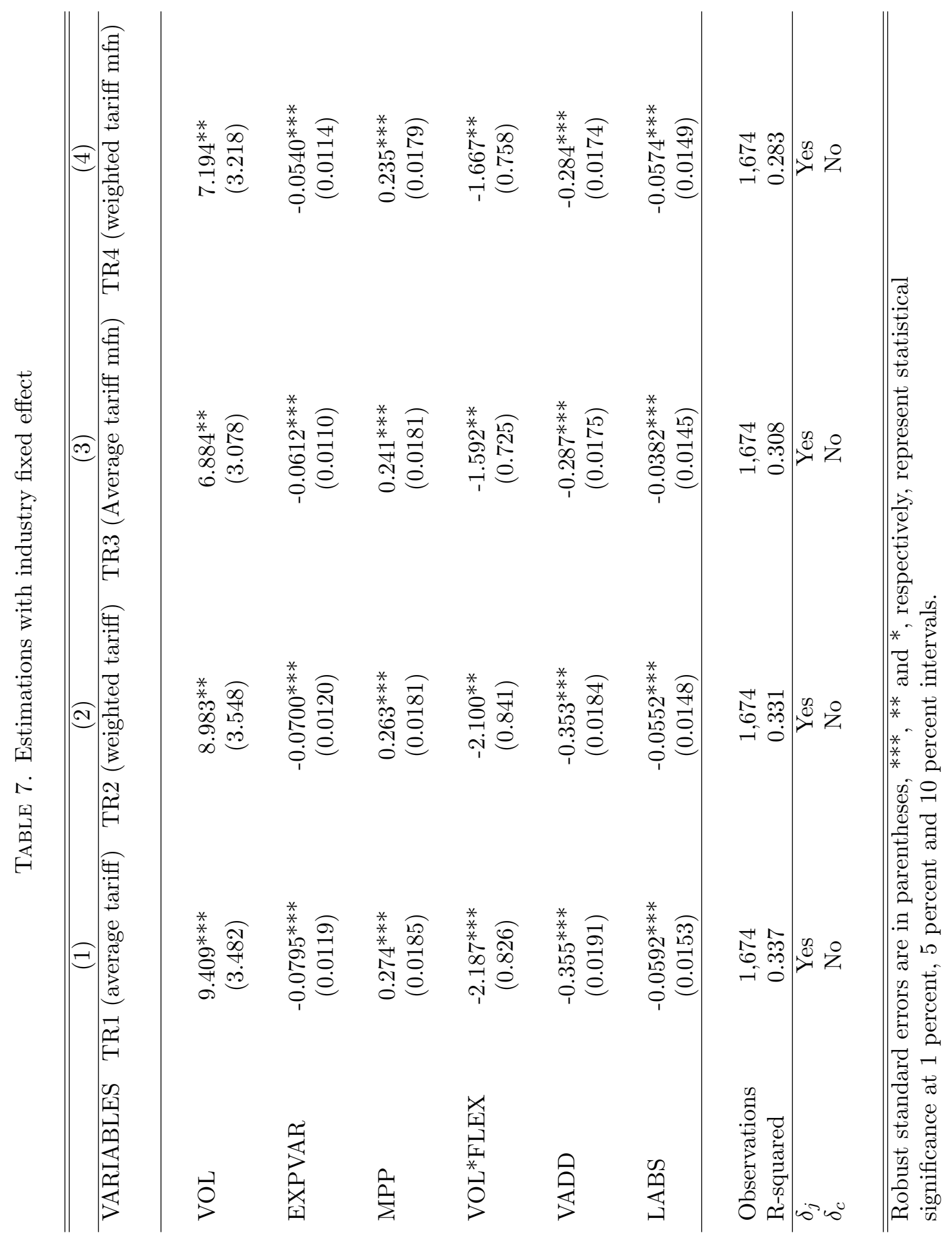




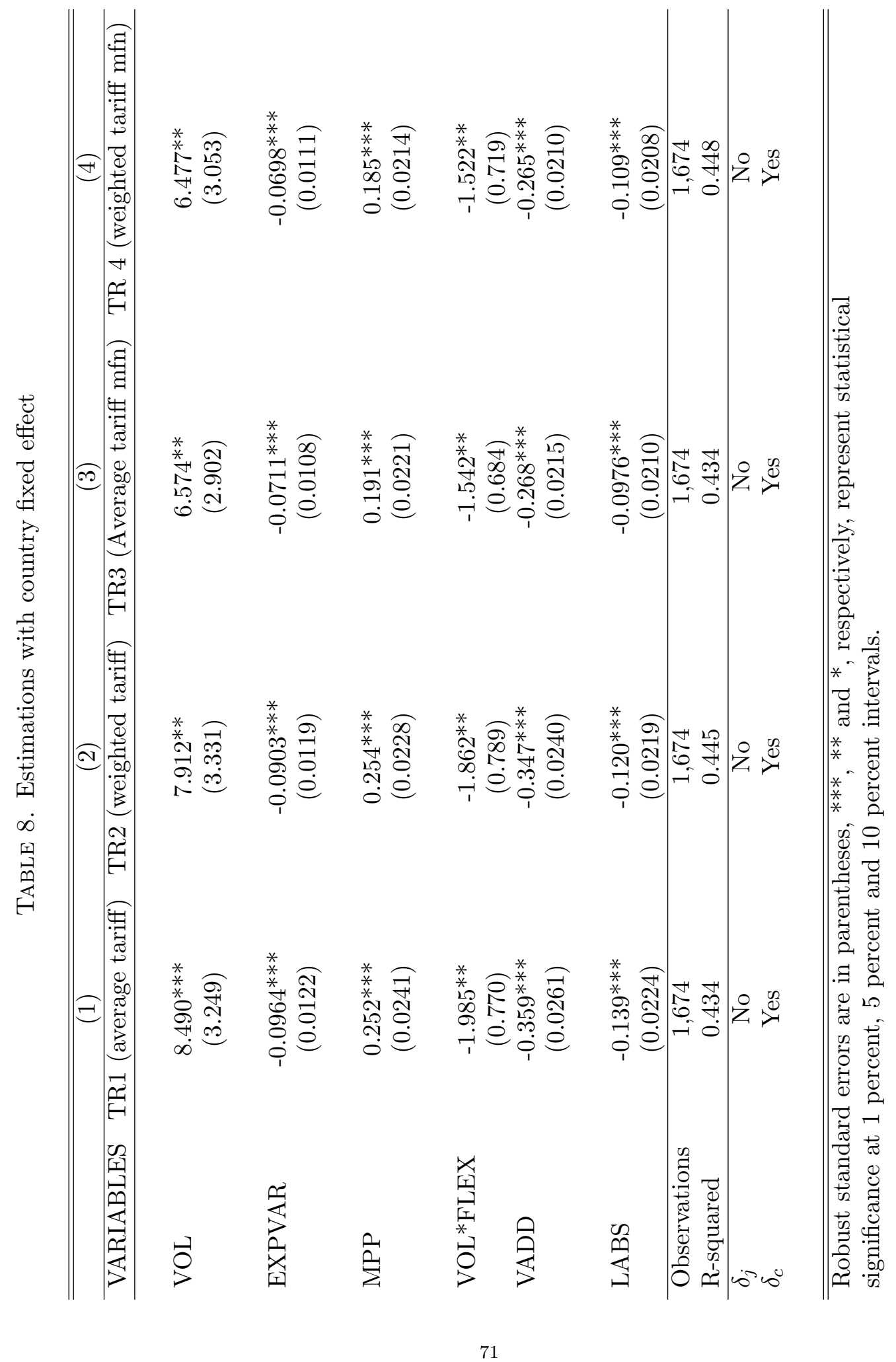




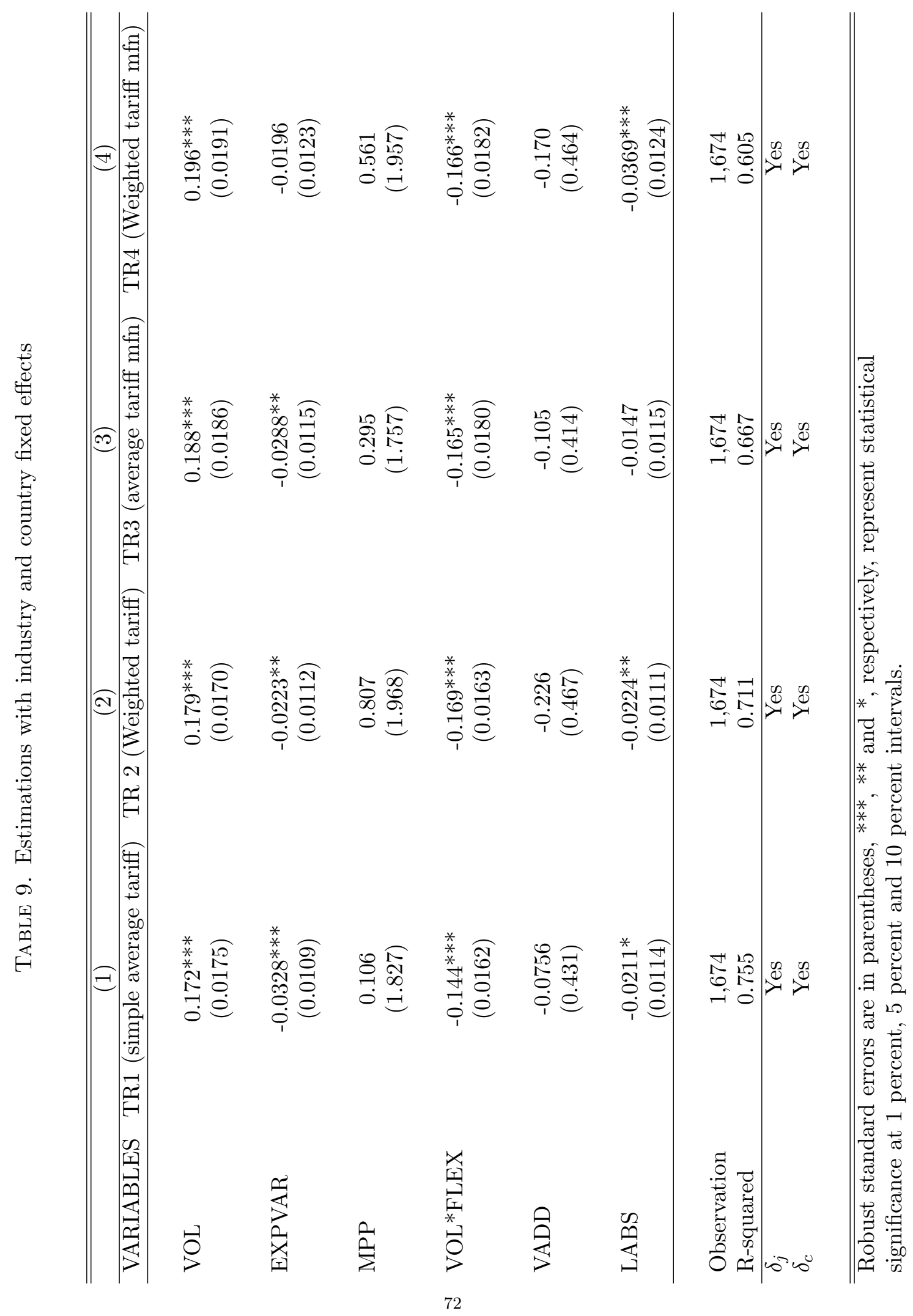




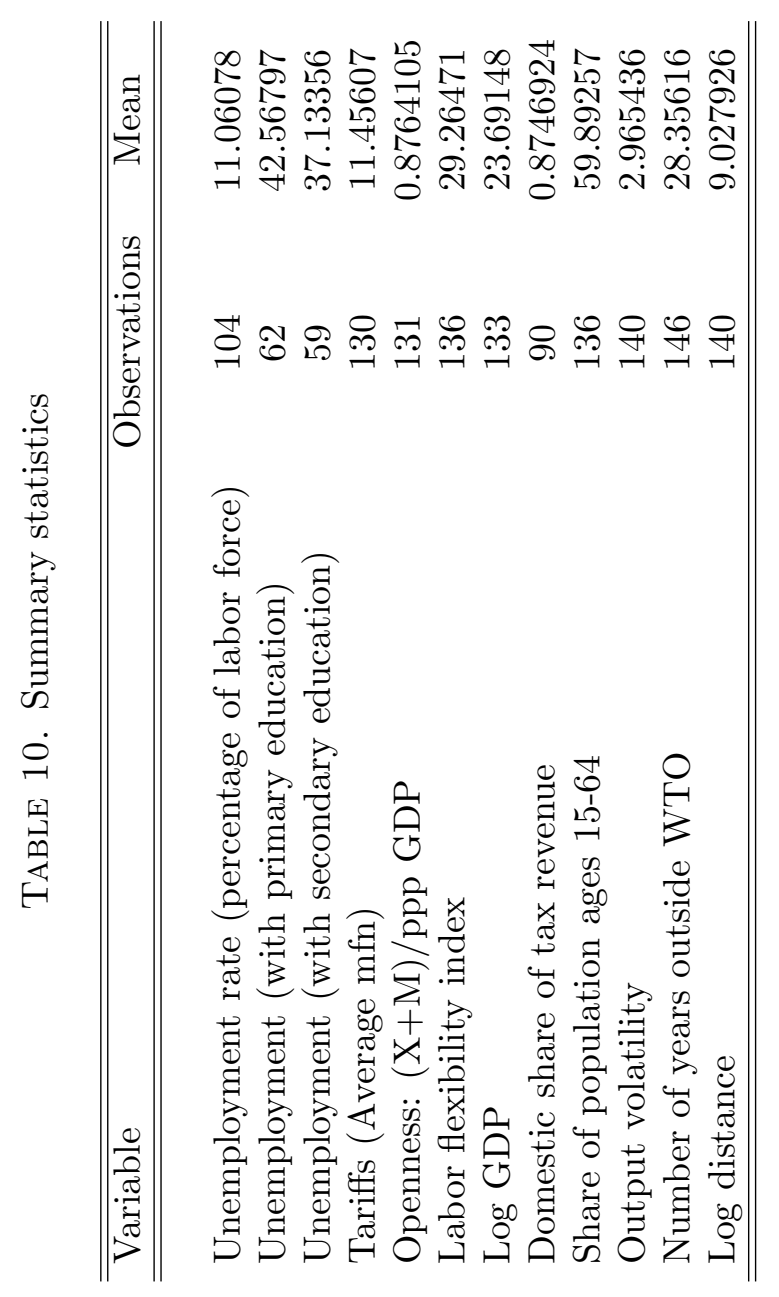




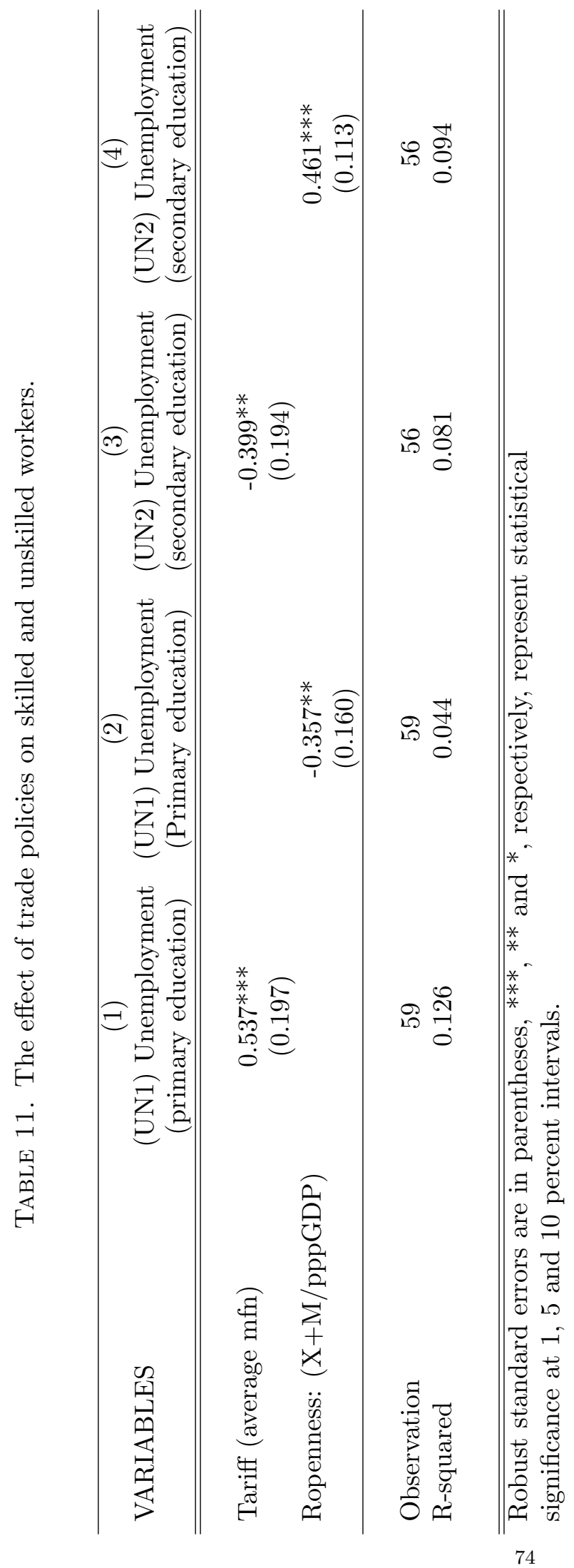




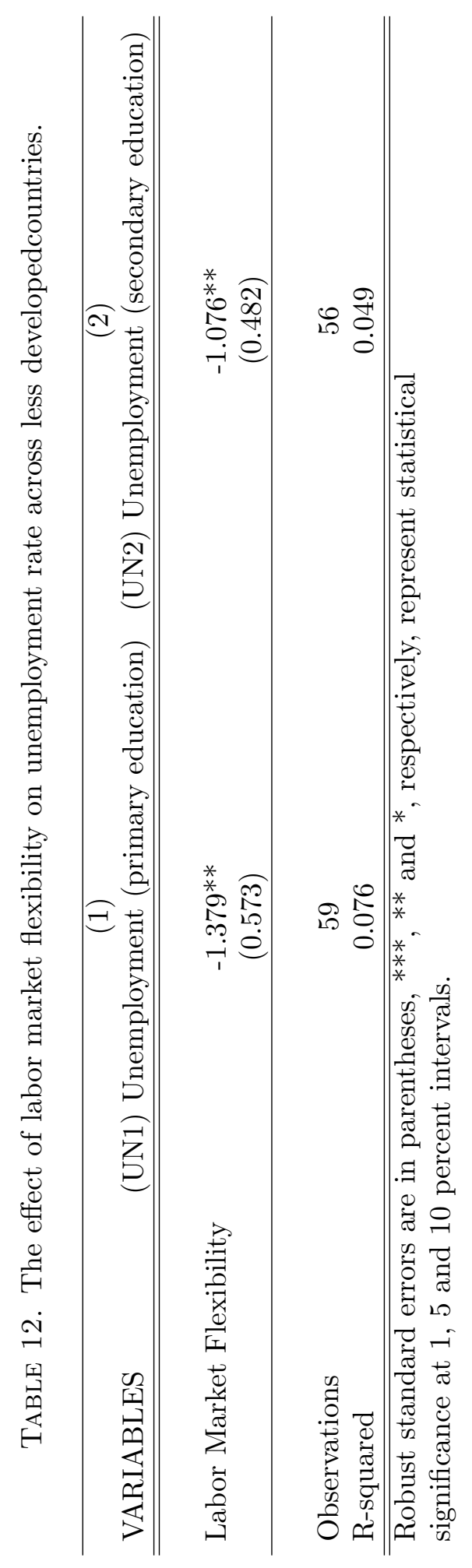




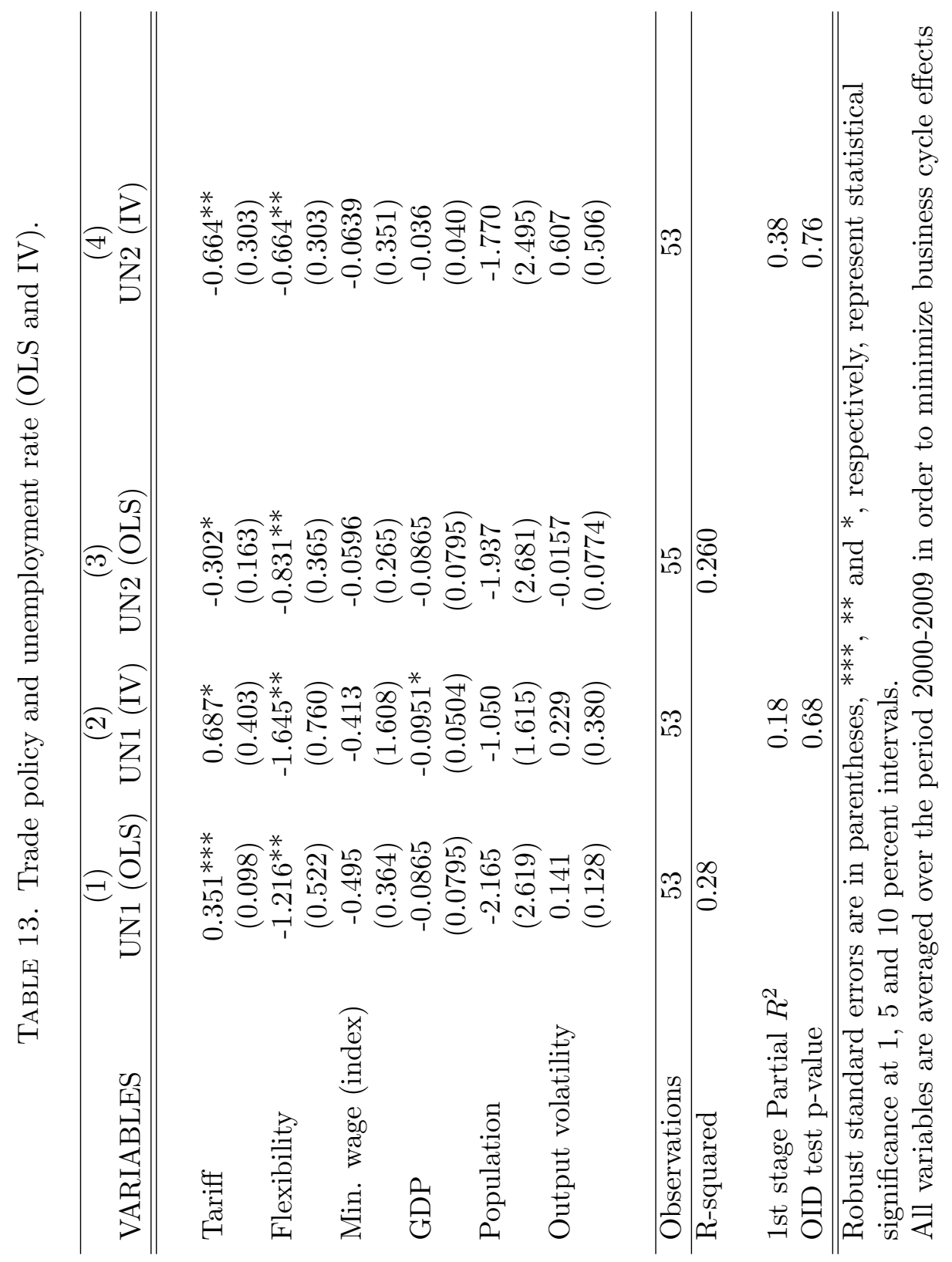




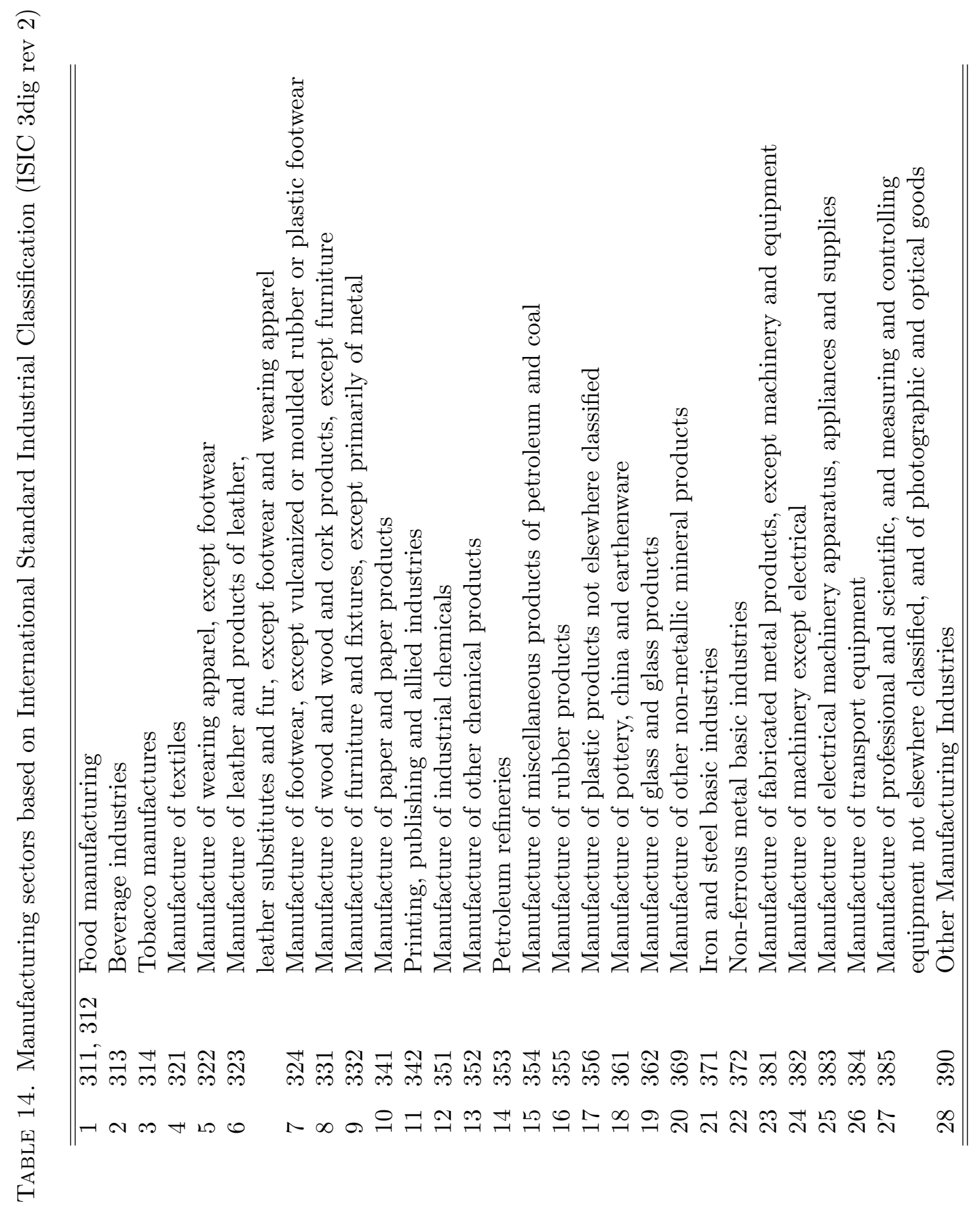

